\title{
Low-cost ceramic membranes: a research opportunity for industrial application
}

S. Mestre ${ }^{\mathrm{a}, \mathrm{b}, ~ *}$, A. Gozalbo ${ }^{\mathrm{a}, \mathrm{b}}$. M.M. Lorente-Ayzac ${ }^{\mathrm{c}}$ E. Sánchez ${ }^{\mathrm{a}, \mathrm{b}}$

${ }^{a}$ University Institute of Ceramic Technology (IUTC), Jaume I University, Av. Vicent Sos Baynat s/n (12006) Castellón, Spain.

${ }^{\mathrm{b}}$ Department of chemical engineering. Jaume I University, Av. Vicent Sos Baynat s/n (12006) Castellón, Spain.

c Asociación de investigación de las industrias cerámicas (AICE). Av. Vicent Sos Baynat s/n (12006). Castellón. Spain.

Corresponding author: smestre@uji.es

\section{SUMMARY}

Obtaining low-cost ceramic membranes has attracted great interest in the scientific community in last years, as it allows to preserve the advantages of ceramic materials while significantly reduce their manufacturing costs. This type of membranes is mainly based on the use of raw materials and manufacturing processes typical of traditional ceramic materials, i.e silicate-based ceramics. This work exhaustively reviews the raw materials, ceramic compositions and variables of the manufacturing processes used in the development of these membranes, with special emphasis on their numerous potential industrial applications.

\section{Introduction}

In practice, a membrane is a barrier that moderates the permeation of species in contact with it. This semipermeable interface can be homogeneous or heterogeneous, dense or porous, organic or inorganic, liquid or solid, etc. The mass transport from one phase to another occurs when a driving force is applied (normally a difference in pressure or concentration). Currently, processes in which 
membrane technology can be used are expanding. The most developed industrial separation processes that make use of membrane technology are microfiltration, ultrafiltration, nanofiltration, reverse osmosis and electrodialysis. It is also being applied in other industrial processes, such as gas separation, pervaporation, membrane reactors, as well as medical applications. According to the material of construction, the main types of membranes are polymeric and ceramic membranes. These latter are manufactured from inorganic materials such as aluminium oxides, zirconia and titania. Ceramic membranes are usually more costly than polymeric ones for the reason that their raw materials are expensive as well as the manufacture complexity. However, ceramic membranes are characterized by a series of advantages such as long-term durability, high mechanical strength, resistance to chemicals and solvents and thermal stability [1-5].

Porous ceramic membranes usually comprise several layers of one or more ceramic materials. They generally consist of a macroporous support, one or more mesoporous intermediate layers and a microporous top layer. Normally, the support provides mechanical strength, while the intermediate layers bridge between the support and the top layer, with the aim of gradually reducing the pore size. The top layer is the selective layer, where the separation process of the membrane takes place (Figure 1).

These asymmetric configurations of porous multilayers are combined to provide ceramic membranes with a wide range of separation performance as set out in Table 1 .

The porous support is usually obtained by conventional ceramic shaping methods and its only function is to support and give mechanical strength to the whole. On this support, one or more intermediate layers are usually deposited, whose missions are to prevent the infiltration of the selective layer in the support, minimize surface roughness and inherent defects in support and provide a smooth and flawless surface for good deposition of the selective layer. The most common methods of layer deposition are dip-coating and casting. Finally, the selective layer is deposited, from which it is necessary to exhaustively control the pore size, because it will determine what will pass through the membrane and what will be retained $[2,5]$. 
The quality of the support is critical, since the defects and irregularities of the support usually produce defects in the layers applied on it; in this way, the supports must be smooth, present a constant and homogeneous surface characteristics (as wettability) as well as a narrow pore size distribution and enough mechanical strength. The porous support can be obtained by different techniques, using powders or suspensions as precursors. The methods usually used for shaping the support are mainly extrusion and pressing, among others, and the choice of one of them is mainly based on the final configuration of the membrane (extrusion for tubular membranes, pressing for flat membranes). The pore sizes usually obtained are greater than $0.1 \mu \mathrm{m}$. In this process, in order to obtain defect-free supports, the adequacy of the powders, especially the granule size (usually between 0.2 and $20 \mu \mathrm{m}$ ) and the incorporation of additives that improve powder processing (deflocculants, plasticizers, binders and lubricants) are of great importance. After shaping the support, the drying and subsequently the sintering are carried out. Drying should be made at a rate that minimizes the appearance of cracks and defects. Finally, the ceramic is thermally treated for sintering; the structure of the firing cycle must ensure the correct elimination of the added organic additives to improve the processing (first part of the firing), together with achieving the desired final properties by sintering (second part of the firing). The density, total pore volume, pore diameter and mechanical strength depend on the maximum sintering temperature (lower than the melting temperature of the material) and residence time at that temperature. Due to the nature of the materials used to obtain the support, the sintering temperatures must be quite high $\left(>1000{ }^{\circ} \mathrm{C}\right)[3,4]$.

Depending on the desired pore size in the selective layer, the required precursors are different, as detailed in Table 2. Ceramic oxide suspensions are used for the preparation of microfiltration and ultrafiltration layers with relatively large pore size. However, it is necessary to apply the sol-gel technology to synthesize layers of smaller pore size: preparation of colloidal sols for ultrafiltration layers of reduced pore size and polymeric sols for obtaining nanofiltration layers.

As set out above, ceramic membranes offer unique advantages in membrane processes due to their excellent properties, such as mechanical strength, thermal stability and chemical resistance under severe conditions (extreme $\mathrm{pH}$, oxidizing agents, etc.), as well as their reduced tendency to 
fouling [2,6]. However, its high price has limited its use in cost-sensitive processes such as environmental applications [3-5]. Ceramic membranes are usually made up of high purity refractory oxides whereas for many applications the benefits provided by these oxides are not necessary, such as, for example, in the treatment of domestic or industrial wastewater, in which the required quality of the treated effluent can be obtained with membranes synthesized with more conventional materials, namely low-cost ceramic membranes. This would imply a significant reduction in raw materials and processing costs, considerably reducing the price of the obtained ceramic membranes.

Low-cost ceramic membranes base their composition on lower-priced raw materials, usually related to traditional ceramic products (tile, sanitaryware, earthenware, porcelain, etc.). Processing of the substrates is also based on the traditional ceramic industry, with pressing and extrusion being the most commonly used forming processes; on the other hand, the sintering temperatures applied are lower than those employed in commercial ceramic membranes, thus reducing processing cost.

Taking as a reference that the prices of ceramic membranes based on alumina and zirconia can lie between 500 and $3000 \$ \cdot \mathrm{m}^{-2}$ [7] and those of polymeric membranes between 20 and $200 \$ \cdot \mathrm{m}^{-}$ ${ }^{2}$ [8-10], there is a wide margin in which low-cost ceramic membranes can be marketed. The approximate price of a commercial alumina membrane is about $500 \$ \cdot \mathrm{m}^{-2}[8,9,11]$, which doubles that of a membrane based on a kaolin-quartz-feldspar composition of $250 \$ \cdot \mathrm{m}^{-2}$ [12]. This price difference is mainly due to the raw materials used and the different conditions along manufacturing process, especially during sintering. The price of alumina is approximately 100 times higher than that of kaolin; moreover, the energy required for sintering an alumina membrane is much higher than that of a kaolin one, due to the difference in temperature that needs to be reached (approximately $1600{ }^{\circ} \mathrm{C}$ for alumina, as opposed to $1200{ }^{\circ} \mathrm{C}$ for kaolin-based compositions). Moreover, kaolin membranes display a lower apparent density $\left(2.7 \mathrm{~g} \cdot \mathrm{cm}^{-3}\right)$ than alumina membranes $\left(3.98 \mathrm{~g} \cdot \mathrm{cm}^{-3}\right)$, therefore the amount of material needed per unit area decreases, reducing the cost of raw materials [13]. 
Thus, the interest in low-cost ceramic membranes has increased in recent years, as they combine the high performance of ceramics with economy. For this reason, great efforts have been made in recent years in the field of membrane technology to develop new porous ceramic materials based on locally available low-cost raw materials such as clay, kaolin, bauxite, diatomaceous earth, andalusite, etc.., [14-23]. These materials are available in abundance and require significantly lower sintering temperatures than those used in commercial oxide membranes. Thus, the mixture kaolin and dolomite was explored as raw material in [16] and [20]. This research emphasized the multiple role of dolomite in the ceramic composition as, on the one hand, it provides adequate porosity and, on the other hand, it acts as a sintering inhibitor. Similar approach was followed in $[7,8]$ but replacing dolomite by calcite as pore former and sintering inhibitor. Also, diatomaceous earth can be used with this same objective as demonstrated by Akhtar et al. [15]. Weir et al. addressed the use of sepiolite clay mineral and showed the benefits of including this highplasticity mineral in the starting composition [19]. Crystalline phases from aluminosilicate raw materials have been also commonly explored in many works such as cordierite ceramics in [13] and mullite ceramics in [14]. Findings showed the good performance of these ceramics for membrane application. Finally, zeolites have been also considered in low-cost ceramic membrane literature $[17,18]$. When using zeolites, micropores associated to these materials are accessible to diffusing molecules therefore applications related with gases can be also contemplated.

The compositions employed in this type of membranes largely depend on the raw materials available in the areas of study, the application for which it is intended, etc. Broadly speaking, there could be two different branches: those compositions based on advanced ceramics (e.g. those containing alumina) with potential applications in very aggressive media and compositions exclusively based on traditional ceramics for applications with lower demanding performance. Although research activity on low-cost membranes has been intense in recent years, due to the numerous potential applications in the industry, very few studies have attempted to correlate the microstructural characteristics of sintered substrates with their functional properties, due to the fact that the use of natural minerals (clay, kaolin, etc.) as raw materials makes it difficult to model the intricate microstructure of these membranes [1,24]. For example, Li et al. [24] applied the 
equations of Carman-Kozeny and Hagen-Poiseuille to relate the membrane permeability and its microstructural parameters, obtaining a good correspondence with the experimental data. Marchese et al. calculated the characteristic parameters of the membranes (hydraulic radius) based on water permeability, as well as different structural characteristics of the membranes (topography, roughness and friction) measured by Atomic Force Microscopy (AFM) [1].

Recently Lorente-Ayza et al. have reported a complete research on the effect of starch on the microstructure of low-cost ceramic membranes [25-27]. The research includes the effect of the nature, amount and particle size of the starch on the microstructure and permeability of different low-cost ceramic membrane compositions. Thus, starch content influences membrane characteristics as porosity, pore size distribution and permeability. In their work, Lorente-Ayza et al. [25] determined that the experimental data of water permeability fit the Hagen-Poiseuille equation confirming the significant contribution of coarse pores generated by starch to membrane permeability. In addition, the effect of starch particle size as well as the influence of fluxing elements present in the starch ashes were also showed by Lorente-Ayza et al. in [26] and [27] respectively.

The development of ceramic membranes based on conventional, naturally occurring minerals could trigger a technological revolution that would provide greater economic value to many natural minerals (widely available throughout the world), as well as to the ceramic companies that process these raw materials. From the above, it can easily be understood the growing interest among the scientific community in research into conventional ceramic raw materials that would allow the design of cheaper ceramic compositions for the manufacture of low-cost ceramic membranes, evaluating the incorporation of numerous raw materials, additives and even residues, both at laboratory and pilot scales.

This review aims to analyze and discuss the research developed in recent years on the raw materials, processes and applications of low-cost ceramic membranes, highlighting the interest of this line of research in the field of membrane separation processes. 


\section{Low-cost ceramic membranes synthesis}

Low-cost ceramic membranes addressed in the literature usually consist of a symmetrical support, directly applied as a microfiltration membrane. In some cases, the support serves as a substrate on which one or more layers are applied, the composition of which can be also based on low-cost raw materials (clays, feldspars, etc., or even some waste) or on raw materials typically used to obtain selective layers (alumina, titania, zirconia, etc.).

\subsection{Raw materials}

The properties of low-cost ceramic membranes are determined by their composition (nature and proportion of raw materials and additives), the content and type of pore-forming materials and the firing cycle (sintering temperature and dwell time). However, the forming method defines the geometry of the final product, and the ceramic composition must be adapted to it $[13,28]$.

Literature reports great variety of raw materials for this type of compositions. For economic reasons, all these raw materials have in common their proximity to the research center, being very diverse their origin: Algeria, India, Argentina, Cameroon, Malaysia, Tunisia, Iran, etc. Clays and kaolins are the most commonly used raw materials due to its optimum characteristics for ceramic processing. As an example, the following tables 3 and 4 show a compendium of some works carried out with clays and mixtures of kaolin+clay.

Mullite-based ceramic membranes represent one of the best alternatives to alumina due to their excellent properties such as low thermal expansion and conductivity, excellent thermal shock resistance and high thermal, chemical and mechanical stability $[39,40]$. Clay minerals must be included in the initial composition to produce the necessary amount of mullite phase. However, membranes prepared with clayey raw materials present disadvantages, such as low porosity, small pore size or high sintering shrinkage, as a result of the high densification rate of clays due to the existence of minor fluxing minerals or impurities in their composition. Thus, N. Saffaj et al. reported the sintering behavior of a filtration support prepared from natural Moroccan clay [41]. The authors emphasized that at certain high temperature the formation of a vitreous mass by silica and some impurities present in the clay lead to porosity and pore size decrease. In the same way, 
J. Zhou et al. stated that it is difficult to get the required properties for membranes based on clay minerals since these minerals can be easily sintered by the action of various existing impurities [18]. P. Belibi et al. also pointed out the marked sintering effect associated to clay-minerals when a local Cameroonian kaolinitic-illitic clay was used to make microfiltration ceramic membranes [32]. According to these authors, the phenomenon is also attributed to the formation of glassy phase from illite mineral which gives rise to a progressive reduction of porosity.

A commonly used strategy to increase porosity and pore size consists in the introduction of different pore forming organic materials, which are named in the tables above and defined in detail in later sections. On the other hand, the addition to the initial composition of minerals containing alkaline earth metals (mainly $\mathrm{Mg}$ and $\mathrm{Ca}$ ), such as wollastonite, calcite or dolomite, may contribute to the reduction of sintering temperature and time, as well as increasing the membrane mechanical strength. Since alkaline earth carbonates are also used as pore formers, their influence on the composition is detailed in later sections. Furthermore, there are different ceramic raw materials, such as feldspars, quartz, bentonites, talcs, etc., which can be added to clays and kaolins to improve membrane processing and properties.

Finally, in recent years there has been an increase in the number of studies valuing wastes in the production of low-cost ceramic membranes, as a main ingredient with diverse functionality or as a pore forming material, depending on the nature of the waste used. Fly ashes from coal-fired power plants, coal gangue and bauxite and diverse phosphate industry sub-products have been reported as ingredients in low-cost ceramic membrane compositions [42].

\subsection{Pore former materials}

Ceramic membranes must have an adequate porosity and pore size, so that their permeability and selectivity are suitable for the separation process for which they are intended. The addition of a temperature-sensitive compound to create porosity is applied both in the manufacture of ceramic membranes based on pure oxides (alumina, titania, zirconia, etc.) and in low-cost membranes. This compound disappears totally or partially during the sintering heat treatment by decomposition, evaporation, liquid phase formation or combustion [43], generating an additional 
porous network that modifies the pore size distribution that could be obtained with the ceramic composition by itself and increasing the permeability of the membrane.

There is a large number of materials that can be used as pore generators, ranging from chemically pure substances as urea [44], processed substances such as starch [45], flour [46], polymethylmethacrylate [47], polystyrene and other materials as coal and their derivatives [48], activated carbon [37,49], natural products such as poppy seeds [50], rice bran [51], millet or corn [48] or even wastes as sawdust $[12,32,52]$. Recently the use of olive stone as pore former material to make low-cost ceramic membranes for a membrane biological reactor (MBR) was reported [53]. The composition of the ceramic membranes was based on agricultural and industrial wastes, such as olive stones (from olive oil production), marble waste powder (from quarrying and processing of marble) and chamotte (from fired tile scrap) together with high-plasticity clay.

Starches and carbonates are the most widely used pore formers. Starch is a natural biopolymer that easily oxidizes (at temperatures close to $500^{\circ} \mathrm{C}$ ), is inexpensive and ecological. However, this substance comes from natural sources (potato, pea, corn, wheat, etc.) and therefore is subject to different extraction and conditioning processes which may affect membrane characteristics. Despite this variability, the nature and properties of starch are not usually considered in low-cost membrane research. Thus, in a study with five different starches Gregorová et al. showed that the mean particle size varied considerably from one starch to another, in values between 4 and 50 $\mu \mathrm{m}$, even modifying the amplitude and shape of the particle size distribution curve (monomodal or bimodal) [45]. Lorente et al. confirmed the variability in starch particle size as well as its effect on membrane microstructure and permeability by comparing six samples of different starches in a clay-based low-cost ceramic membrane composition [26]. As observed in Figure 2, a starch of large particle size (average diameter of $50 \mu \mathrm{m}$ ) is required to significantly increase the permeability of membranes. As the most frequent average size of commercial starches lies between 20 and $50 \mu \mathrm{m}$ it is necessary to carefully select the particle size of the starch in order to induce significant changes in membrane permeability. Also, the influence of starch ash from different starches (corn, potatoes, wheats and pea) on membrane characteristics has been recently reported as displayed in Figure 3. This figure shows the variation of air permeability with sintering 
(dwelling) time for a clay-based low-cost ceramic membrane composition prepared from the same amount of starch but of different nature. As observed, the figure highlights that there is a nonnegligible effect of the starch ash on the sintering behavior and consequently on membrane microstructure and permeability [27].

Nevertheless, the parameter with the greatest influence on permeability and pore size is the proportion of starch added to the composition. In order to reach the optimum level of permeability, the proportion added usually varies between 2 and $20 \mathrm{wt} . \%$. Thus, by adjusting the amount of starch added, a wide range of pore size and permeabilities can be obtained. For example, the average pore size of alumina membranes varies from 1 to $2 \mu \mathrm{m}$ and porosity increases from 23 to $44 \%$ as the amount of starch grows from 0 to $15 \mathrm{wt} . \%$ [54], while in clay membranes porosity increases from 9 to $32 \%$ as the proportion of starch augments from 0 to $35 \mathrm{wt} . \%$ [55]. As shown in Figure 4a and 4b, Lorente-Ayza et al. reported the effect of the amount of corn starch on the microstructure of alumina-kaolin low-cost ceramic membranes [25]. On the one hand, porosity significantly increases, and pore size distribution broadens by introducing starch in the membrane composition as revealed by the marked arrow in the mercury pore size distributions (Figure 4a). On the other hand, Figure $4 \mathrm{~b}$ displays the relation between membrane air permeability and the amount of starch added for two sintering temperatures $\left(1200{ }^{\circ} \mathrm{C}\right.$ and $\left.1400{ }^{\circ} \mathrm{C}\right)$. Thus, based on a percolation model, the authors estimated that a threshold amount of starch around $10 \mathrm{wt} . \%$ was necessary for an effective interconnection of the pore network created by the pore former, in terms of permeability increase.

These same authors explain the mechanism of pore formation from starch addition. Thus, the membrane without starch exhibits a bimodal pore size distribution, as a result of its composition: small pores (around $0.1 \mu \mathrm{m}$ ) mainly caused by the porosity of the matrix made up of decomposed kaolin particles and large pores (around $0.45 \mu \mathrm{m}$ ), generated between the decomposed kaolin and alumina particles. The pore size grows (around $0.7 \mu \mathrm{m}$ ) and the pore size distribution becomes wider when reduced amounts of starch are added to the composition (less than $10 \mathrm{wt} . \%$ ). Nevertheless, the bimodal distribution becomes trimodal as well as the pore size dramatically increases when starch is added to the composition in high proportions (more than $10 \mathrm{wt} . \%$ ). This 
is because over this percentage of starch the large pores generated by starch burning out start to create a connected network accessible to fluids. Similar findings concerning a $10 \mathrm{wt} . \%$ starch content threshold was reported by G.C.C. Yang et al. with alumina-bentonite membranes [54]. According to these authors, the packing of alumina particles in the green specimens were disrupted by the larger starch agglomerates. As the starch content increased over $10 \mathrm{wt} . \%$ a greater number and degree of contacts among the individual alumina-starch shells resulted in a larger nominal pore size and porosity. In a recent paper D.O. Obada et al. have confirmed the pore interconnection mechanism associated with pore former addition [56], by using powdery high density polyethelene (PHDPE) as porogen agent. Thus, the authors showed that the addition of sufficient amount of PHDPE (20 wt.\% was considered optimum) increases porosity and pore size as well as pore connectivity, owed to the increase of interconnected pores created by pore former burnout which gave rise to an increase of permeability.

Sánchez et al. also confirmed the effect of the amount of pore former on membrane permeability in the aforementioned research on low-cost ceramic membrane based on olive stone recycling [53]. Hence, as observed in Figure 5, the amount of recycled material as well as the sintering temperature largely affected the water permeability of the obtained membranes.

Alkaline earth carbonates (calcite, magnesite and dolomite) are also commonly used as poreforming materials. The decomposition temperatures of calcite and magnesite are, respectively, 920 and $630{ }^{\circ} \mathrm{C}$; dolomite decomposes in two stages, at 730 and $930{ }^{\circ} \mathrm{C}$ [57]. However, the decomposition of calcium or calcium-magnesium carbonates can produce a double effect, since at low temperatures $\left(<1000{ }^{\circ} \mathrm{C}\right)$ large pores form, which are reduced at higher temperatures $(>$ $1300^{\circ} \mathrm{C}$ ) as a consequence of the sintering mechanism in the presence of liquid phase induced by alkaline earth oxides content [58-60]. Recently, studies by Harabi et al. and Boudaira et al. showed that the addition of calcium carbonate to a kaolin-based composition allowed to obtain ceramic materials based on mullite, without the appearance of the cristobalite phase, undesirable due to its high coefficient of thermal expansion $[13,61]$. However, the effect of carbonates on the properties of membranes depends on their nature, proportion and membrane composition. Thus, for example, in a kaolin-based composition, the addition of calcium carbonate in proportions of 
5 to $20 \mathrm{wt} . \%$ produces an increase in porosity from 51 to $55 \%$ and in pore size from 5.2 to 8.6 $\mu \mathrm{m}$. For higher additions, there is a minimum porosity of $50 \%$ at $25 \mathrm{wt} . \%$ content; however, the pore size continues to increase, reaching values of $17.6 \mu \mathrm{m}$ for $30 \mathrm{wt} . \%$ content [13]. Nevertheless, the use of these pore-forming materials whether organic or inorganic in nature that decompose during membrane sintering implies the need to design very slow firing cycles to prevent cracks and defects, which has a negative effect on processing cost.

\subsection{Support fabrication}

The composition of the ceramic membrane is the main factor conditioning the sintering cycle, as well as its microstructure and price. However, the method of fabrication of the substrate determines the final geometry of the product, also having a great impact on the microstructure and, consequently, on the properties and performance of the final product [62-64]. Thus, recently Lorente et al. have compared the microstructure and characteristics of clay-based, low-cost ceramic membranes compositions formed by uniaxial pressing and extrusion [65]. In this research, the authors analyzed the impact of the shaping method in compositions with starch and variable amount of clay ranging from 40 to $85 \mathrm{wt} . \%$. Figure 5a shows the sintered microstructure of pressed and extruded pieces for the composition with the highest amount of clay. As it can be observed, the microstructure of the extruded specimen clearly differs from that of the pressed counterpart. Hence, the extruded microstructure shows an orientated pore distribution, which follows a helical profile because of the movement of the colloidal clay particles travelling through the extruder auger. In addition, pores display lower connectivity when compared with pressed microstructure. Consequently, fluid transport properties of membranes were also influenced by the shaping method. As displayed in Figure 3b, permeability dramatically decreases as the clay content in the starting composition grows. However, for any clay content, extruded pieces are always less permeable than pressed specimens, while this difference is amplified as the clay content in the starting composition increases.

Ceramic membranes usually present different configurations, establishing two main groups: flat discs and tubular membranes $[66,67]$. There are other more complicated configurations, such as multichannel monoliths (honeycombs) and hollow fiber modules, which can be considered 
variations of tubular forms. Powder pressing and extrusion (for tubular geometries) represent the common forming methods reported, with a minority of studies using slip casting $[32,37,38,49,68]$, and very rarely the phase inversion technique [69].

The following figure illustrates the stages of the pressing and extrusion processes used for obtaining low-cost ceramic membranes. After dry homogenization of the raw materials, the composition is conditioned to accomplish with the selected forming process. After forming, the obtained support is dried and then sintered.

\section{i. Dry uniaxial pressing}

Uniaxial pressing is used to obtain simple geometries such as flat membranes and circular supports. It is an inexpensive technique and suitable for large production volumes [67]. After mixing the raw materials, the composition must be conditioned for subsequent forming. This includes the possible addition of water and/or organic binders (polyvinyl alcohol, polyacrylic acid, polyethylene glycol or methylcellulose) in appropriate proportions $[6,9,67]$, which increase the mechanical strength of the unfired support. The binder must be completely removed during sintering without leaving residues or ashes on the final support. The material is then compacted by uniaxial pressure applied by a plunger or piston; the pressure used depends on the composition, the compacted area and the final characteristics of the substrate and, according to the literature, ranges from 20 to $200 \mathrm{MPa}$. As the applied pressure increases, there is an enhancement in the unfired mechanical strength of the substrate, as well as a reduction in pore size; however, a maximum pressure exists beyond which an increase in the applied pressure does not produce further microstructural changes $[67,70]$. In pressing, the internal friction forces are high, as the particles rub against each other, therefore the energy needed to form the part is greater than that in extrusion process [66].

\section{ii. Extrusion}

Compositions containing clay present better characteristics for extrusion forming, due to the plasticity of this material, which allows to obtain a paste that can be shaped with relatively low extrusion pressure. However, different additives are usually added to extruding compositions, such as binders, plasticizers and lubricants which give the pastes the suitable rheological behavior 
for extrusion, minimizing the appearance of defects and cracks. Normally, cellulose derivatives as binders (methylcellulose, carboxymethylcellulose, etc.) and organic polymers as plasticizers or lubricants (polyvinyl alcohol, polyethylene glycol, etc.) are commonly employed $[5,14,67]$. There are also starch products that are used in numerous works as binders (e.g., amijel Cplus 12072, Cerestar) [13,14,23,61,71].

After mixing the composition with appropriate additives and water, it is kneaded until a highly viscous paste is obtained. After kneading, a homogenization or ageing stage should be carried out [5]. Finally, shaping of the support takes place, normally, in an auger extruder, usually under vacuum conditions in order to reduce the amount of air contained in the paste. In extrusion, the ceramic paste is forced to pass through a die by applying a force with the help of an endless screw. The geometry of the die determines the final configuration of the support (flat, multichannel tubular, honeycomb structure, etc.). The dough is transported against the internal friction forces (between the particles and the wall) and against the friction forces with the die walls. Extrusion pressure and rate are the main variables to control the process. Nature (plasticity) of the material, particle size and water content are the key compositional characteristics for the extrusion process $[5,66,67]$.

\section{iii. Other forming methods.}

In addition to the shaping methods described previously, some alternative forming procedures has been proposed for membrane manufacture as slip casting, freeze casting or tape casting (figure10). The slip-casting technique is one of the more traditional ceramic shaping processes and is well established for preparing ceramic samples with complex shape and high homogeneity. The slip is poured into a porous mold, usually made of plaster of Paris. Water from the slip is absorbed by the mold, leading to the formation of a solid layer on the mold walls. The thickness of this solid layer is related to the time in which the slip is kept in the mold. When the desired wall thickness is reached, the excess slip is removed, and then the piece demolded, dried and sintered [72]. The freeze-casting (also known as ice templating), is a technique that consists of freezing a liquid suspension, followed by sublimation of the frozen solvent under reduced pressure. This allows controlling size, shape, local distribution and orientation of pores [73]. Concretely, the porous 
structure is almost a direct replica of the frozen solvent crystals. During freezing, the dispersed particles are redistributed by the moving solidification front. Thus, the final morphology of the porous ceramics and the structure of the solidification front are directly related to the interaction between the dispersed particles and the solvent. In addition, the final porosity can be tuned by varying the solids loading of particles in the suspension, and the size of the pores is influenced by the freezing kinetics. Due to the directional solidification of the solvent, the porous channels of the resulting ceramics can run directionally from the bottom of the sample to the top [74].

Tape casting is a standard shaping technique used to produce flat ceramic sheets. This method consists of a wet-shaping process based on casting of a tape from a slip with pseudoplastic behavior. The slip is composed of an inorganic powder dispersed in a liquid (water or organic), which acts as a solvent for organic additives (dispersants, plasticizers, and binders) and as a dispersion medium for the ceramic particles. The prepared slurry is poured into a container and after casting, the tape is formed onto a moving polymer tape, where a leveling blade, commonly named "doctor blade", controls the thickness of the green tape. The green tape is dried and cut into parts, then sintered to remove organics and promote the desired densification [75].

\section{iv. Drying and sintering}

After the shaping of the substrate, it is dried and sintered to provide the desired final properties. Drying is usually carried out in two stages. In the first stage, the supports remain at room temperature for a certain period (usually 24 hours); they are then placed in a stove at a higher temperature (between 100 and $200{ }^{\circ} \mathrm{C}$ ) for a time ranging from 24 to 48 hours. The first stage corresponds to the elimination of the interstitial water that fills the space between the particles, and the greatest contraction occurs during drying. In the second stage, the adsorbed water is eliminated, and the drying contraction attributed to it is reduced. This procedure is carried out with the substrates formed both by pressing and extrusion, in order to guarantee that the substrates are free of cracks and defects, although in the case of pressing forming it can be simplified, as a result of the much lower amount of water in the starting powder. In some cases, as tubular supports, drying is carried out inside rotating rollers to avoid curvatures and warps [5,57]. 
Firing represents the final step in the manufacture of low-cost ceramic membranes, giving rise to a material with the desired final properties. The thermal cycle is defined by the maximum firing temperature and the dwell time at that temperature, as well as by the heating rate; furthermore, constant temperature dwellings can be introduced at lower temperatures for a given time. The firing cycle must be defined in such a way as to allow the elimination of additives and pore formers introduced into the composition, as well as to favor the reactions that take place between raw materials. Normally, the cycles used are divided into two stages: the first corresponds to the combustion of organic materials (with a low heating rate, between 1 and $5{ }^{\circ} \mathrm{C} \cdot \mathrm{min}^{-1}$, to minimize the appearance of cracks or defects due to rapid combustion), and the second allows sintering of the ceramic by densification and grain growth. The maximum temperature and residence time used condition the properties of fired substrates: apparent density, porosity, pore size distribution, mechanical resistance, permeability, etc. [5,57].

When modifying the maximum temperature of the thermal cycle, the properties of the ceramic membranes vary. Usually, as the temperature increases, the porosity decreases and the pore size distribution shifts to larger sizes. However, the amplitude in the variation of properties when modifying the firing temperature depends to a large extent on the composition of the membrane. Membranes with clay-based compositions show a reduction in porosity from 19 to $16 \%$ when the sintering temperature increases from 1000 to $1300{ }^{\circ} \mathrm{C}$ [76]. Other membranes with compositions based on mixtures of kaolin, quartz and carbonates show a similar trend: porosity decreases from 40 to $22 \%$ as sintering temperature increases from 900 to $1000{ }^{\circ} \mathrm{C}$, while pore size augments from 2.6 to $5.5 \mu \mathrm{m}$ [8]. Similar trends have been found in more complex membranes, based on mixtures of kaolin, pyrophyllite, feldspar, clay, quartz and calcite, in which porosity shows a maximum between 41 and $46 \%$ when firing temperature increases from 850 to $1000{ }^{\circ} \mathrm{C}$, while the mean pore diameter grows from 0.87 to $1.1 \mu \mathrm{m}[9]$.

\subsection{Deposition of selective layers}

As mentioned above, low-cost ceramic substrates can be used directly as microfiltration membranes. However, selective layers can also be applied to them, which reduce the effective pore size of the membranes and allow them to be used in other separation processes. The 
composition of these layers may be based on ceramic oxides such as alumina, zirconia or titania $[30,37,77-79]$, on zeolites $[38,80]$, or also on low-cost ceramic materials.

The composition of low-cost selective layers is usually similar to that of the substrate on which they are applied; in this way, the probability of cracks and fissures forming during sintering of the asymmetric membrane minimizes. Thus, layers have been obtained from Tunisia clay $[31,81]$, kaolin from Algeria [71], lime loams [82], apatite [83], anorthite [84], diatomaceous earth [85], phosphates [86] and even compositions with different raw materials (clay, bentonite, alumina and quartz) [34] or residues from the phosphate industry [87].

Layer composition particle size is one of the main factors which controls porosity and pore size of selective layers. The grinding of raw materials is usually carried out in ball mills, in an aqueous medium, with milling times ranging from 2 to 48 hours, obtaining particle sizes lower than $10 \mu \mathrm{m}$ [34]. In order to improve the rheological properties of the suspensions and obtain layers with homogeneous properties, it is necessary to incorporate additives such as deflocculants (sodium silicate, sodium carbonate, etc.) and dispersants (carboxylic acids); on the other hand, the addition of binders (usually polyvinyl alcohol, PVA, which also acts as a plasticizer) improves the adhesion and finish of the obtained layers. In many of the reported studies, the prepared suspensions usually consist of between 5 and 15 wt. $\%$ of raw materials, 28 and 40 wt. $\%$ of a 12 wt.\% aqueous solution of PVA, to which the necessary additives have been added $[31,71,82$ 84,86]. Thus, Khemakhem et al. prepared an ultrafiltration layer using the following formulation: 1.5 wt.\% illite, $62.5 \mathrm{wt} . \%$ hydroxyethylcellulose suspension at $2 \mathrm{wt} . \%, 4$ wt.\% polyethylene glycol and $32 \mathrm{wt} . \%$ of an aqueous solution of a $0.1 \mathrm{wt} . \%$ dispersant agent [31].

The layers are applied by dip-coating; the flat supports are introduced into the precursor suspension, removing them after a certain contact time, as shown in Figure 11 [88]. In tubular supports, the layer can be applied inside the tube (usual arrangement) or outside. If it is applied to the outside, the procedure to be followed is similar to that of flat supports, after sealing both openings of the tubular support. For the application of the layer on the inner surface, these are vertically arranged, and the lower opening of the tube is sealed; the support is then filled with the suspension, which remains in contact for a certain time after which the suspension is drained from 
the lower part of the tube [86]. The contact time between the suspension and the support can range from few seconds to ten minutes. However, because the thickness of the layer obtained depends on the solids content of the suspension and the deposition time, these parameters are related; Almandoz et al. reduced the contact time to 13 seconds by increasing the solids content to 50 wt.\% [34]. Other factors influencing the thickness and morphology of the resulting layer are the viscosity and density of the suspension, as well as the speed of substrate extraction.

After deposition, the as-deposited layer is dried at room temperature for a long period (between 12 and 24 hours). The layer is then sintered. Some reported characteristics of the firing cycles for selective layer sintering are as follows: slow heating rate $\left(1-4{ }^{\circ} \mathrm{C} \cdot \mathrm{min}^{-1}\right)$ to avoid cracking, maximum sintering temperature lower than that of the substrate and dwell time between 1-2 hours. In addition, the firing cycle must include a long dwell time (1-2 hours) at $250^{\circ} \mathrm{C}$ to eliminate the added additives (polyvinyl alcohol). The maximum sintering temperature of the layer determines the properties of the membrane, as well as improves the adhesion between the substrate and the layer. Finally, when making a multilayer membrane, each layer must be sintered after application; in this case, the sintering temperature of a given layer must be higher than the sintering temperature of the subsequent layer.

\section{Characteristics of low-cost ceramic membrane supports}

Despite the fact that a ceramic membrane is based on a multilayer assembly, most of the low-cost ceramic membrane literature has focused on the characteristics and properties of the ceramic supports due to their potential application as microfiltration membranes. Besides, it is also of special interest to evaluate the properties of low-cost ceramic substrates, as they condition some of the final properties of the membrane, such as permeability and mechanical strength. The following tables summarize the main characteristics of some of the low-cost ceramic substrates developed in the literature from clay minerals or kaolin and formed by pressing (Table 5) and extrusion (Table 6): pore size, porosity, water permeability and mechanical strength.

Pore size and porosity vary over a wide range of values, due to their dependence on the particle size of the starting raw material, the percentage of pore-forming materials added, the forming 
process and the sintering cycle, especially the maximum temperature. Likewise, water permeability fluctuates between very different values, due to its close relationship with porosity and pore size. Finally, the mechanical strength of low-cost ceramic membranes is in the same range as microfiltration ceramic membranes based on alumina, which usually have values higher than $50 \mathrm{MPa}[69]$.

Although many works only focus on the composition design and membrane characterization, many other emphasize the relationship between microstructure features and filtration performance. Thus, M. Rawat et al. optimized a ceramic composition mainly comprising kaolin and fly ash [89]. The selected membrane resulted in a good combination of pore size $(0.885 \mu \mathrm{m})$, porosity $(42.7 \%)$, mechanical strength $(43.6 \mathrm{MPa})$ and chemical stability $(<3 \mathrm{wt} . \%$ loss in acid and $0.02 \%$ in alkali). This membrane was successfully applied in the separation of humic acid from water while high flux recovery was also reported. In a recent research, S. Saja et al. designed low-cost ceramic microfiltration membranes based on natural perlite and corn starch [90]. Some characteristics of the membrane were: $52.1 \%$ porosity, an average pore size of $1.7 \mu \mathrm{m}, 1433 \mathrm{~L} \cdot \mathrm{h}^{-}$ ${ }^{1} \cdot \mathrm{m}^{-2} \cdot$ bar $^{-1}$ water permeability and a mechanical strength of $21.7 \mathrm{MPa}$. Good chemical resistance both in acidic and alkaline medium was also reported. With this membrane, the authors obtained a retention of turbidity of $97 \%$ and $96 \%$ for agro-food and tannery effluents respectively by frontal microfiltration mode. M. Issaoui et al. developed low-cost tubular microporous supports for ceramic membranes by extrusion from a powdery mixture containing kaolin, starch and sand [91]. Results confirmed that tubular supports for membrane elaborated from a paste containing $87 \mathrm{wt} . \%$ kaolin $+10 \mathrm{wt} . \%$ starch $+3 \mathrm{wt} . \%$ sand presented the best performance by featuring a permeability of $221 \mathrm{~L} \cdot \mathrm{h}^{-1} \cdot \mathrm{m}^{-2} \cdot \mathrm{bar}^{-1}$. In these conditions, membrane was found to be suitable for algal separation as well as easily cleaned by water. Ceramic microfiltration membranes from a kaolin-quartz-calcium carbonate mixture were developed by D. Vasanth et al. [8]. The membrane sintered at $900{ }^{\circ} \mathrm{C}$ (porosity of $30 \%$, average pore size of $1.3 \mu \mathrm{m}$ and flexure strength of $34 \mathrm{MPa}$ ) was inferred as an optimum membrane for microfiltration applications. Filtration results showed a maximum rejection of $85 \%$ and $99 \%$ for oil (feed oil concentration of $250 \mathrm{mg} \cdot \mathrm{L}^{-1}$ ) and bacteria (feed bacteria concentration of $6 \cdot 10^{5} \mathrm{CFU} \cdot \mathrm{mL}^{-1}$ ) respectively. Emani et al. addressed the 
preparation of microfiltration membranes from mixtures of kaolin, quartz and calcium carbonate [6]. The prepared membranes possessed porosity ranging from $35.4 \%$ to $39.4 \%$, average pore size varying from 0.9 to $1.85 \mu \mathrm{m}$ and flexure strength ranging from 7.8 to $11 \mathrm{MPa}$. The optimum membrane provided a transmembrane flux of 90 to $44 \cdot 10^{-6} \mathrm{~m}^{3} \cdot \mathrm{m}^{-2} \cdot \mathrm{s}^{-1}$ at $206.7 \mathrm{kPa}$ with an enzyme-treated centrifuged juice, and a negligible alcohol-insoluble solids content in the permeate. Alumino-silicate compositions were also used by M. C. Almandoz et al. [92]. Their results indicated that an appropriate election of the particle size of the raw materials as well as of the sintering temperatures allows to obtain membranes with mean pore sizes within the range from 0.1 to $1 \mu \mathrm{m}$ that make them suitable for microfiltration. Tests with synthetic aqueous solution containing microbial charge revealed good membrane selectivity with a microorganism rejection higher than $90 \%$.

\section{Comparison between properties of commercial ceramic membranes}

\section{and those based on low-cost raw materials incorporating selective layers}

Low-cost ceramic membranes possess the characteristics of ceramic materials: chemical stability, high mechanical resistance, brittleness, thermal and electrical insulation, etc. However, due to the difference in raw materials and manufacturing processes, the properties of low-cost ceramic membranes differ from those of commercial ceramic membranes based on pure oxides. As already indicated, commercial membranes usually consist of substrates and selective layers, their pore size being at least lower than $10 \mu \mathrm{m}$, and most of them lower than $1 \mu \mathrm{m}$, as set out in Table 7 . On the other hand, as set out above most of the low-cost ceramic membrane literature has focused on the characteristics and properties of the ceramic support due to the potential application as microfiltration membrane. Nevertheless, as shown in Table 8 many other works have addressed to develop multi-layer assemblies by depositing some low-cost selective layers on the microfiltration support to enhance microfiltration performance or, more interestingly, to reach ultrafiltration range. As observed in these tables (7 and 8), properties of commercial and low-cost ceramic membranes display similar variability ranges. Porosities of commercial membranes, 30- 
$40 \%$, are slightly lower than those of low-cost membranes (40-50\%) while water permeability values lie at similar intervals, all below $1000 \mathrm{~L} \cdot \mathrm{h}^{-1} \cdot \mathrm{m}^{-2} \cdot \mathrm{bar}^{-1}$.

Thus, Khemakhem et al. developed defect-free illite ultrafiltration membranes by slip-casting [31]. The most concentrative pore diameter of composite membranes was about $15 \mathrm{~nm}$. Moreover, the illite-based membranes possessed high thermal stability. These ultrafiltration membranes can be used as support materials for a nanofiltration layer or directly for solution purification. The average permeability was about $88 \mathrm{~L} \cdot \mathrm{h}^{-1} \cdot \mathrm{m}^{-2} \mathrm{bar}^{-1}$. The molecular weight of the dextran whose retention reached $90 \%$ was taken as the molecular weight cut-off, obtaining a value of $185 \mathrm{kDa}$. This value agreed with the pore size measured by nitrogen adsorption-desorption experiments. B. Ghouil et al developed multilayer (3-layers) microfiltration membranes from alumino-silicates (kaolin and calcium carbonates mixtures) [71]. A ceramic support featured by a porosity of $47 \%$ and an average pore size of $8 \mu \mathrm{m}$ with an intermediate layer of about $0.5 \mu \mathrm{m}$ of average pore size was coated by an alumino-silicate selective layer of $40 \mu \mathrm{m}$ thickness and an average pore size of $0.2 \mu \mathrm{m}$. The intermediate layer had also the role of preventing the infiltration of suspensions into the support, allowing a reduction of the thickness of the top layer and eliminating the defects of the support (surface roughness reduction). The water permeability of the multilayer assembly was about $550 \mathrm{~L} \cdot \mathrm{h}^{-1} \cdot \mathrm{m}^{-2} \cdot \mathrm{bar}^{-1}$, whereas the microfiltration performance of the membrane with dextran solution was demonstrated.

In another work, Khemakhem et al. designed a multilayer microfiltration membrane from Tunisian natural materials [81]. The support showed mean pore diameter and porosity of about $6.3 \mu \mathrm{m}$ and $49 \%$, respectively. The pore diameters measured for the microfiltration layer were centred near $0.18 \mu \mathrm{m}$. A defect-free membrane was only obtained for selective layer thickness less than $10 \mu \mathrm{m}$. Results proved well the efficiency of these microfiltration membranes. Nevertheless, these membranes can also be used as a support for an ultrafiltration layer. In [83] Masmoudi et al. developed a hydroxyapatite-based multilayer membrane with the following characteristics: average pore diameter of $0.50 \mu \mathrm{m}$; average apatite layer thickness of $32.5 \mu \mathrm{m}$ and a porous volume of $48 \%$. A stabilized flux of $120 \mathrm{~L} \cdot \mathrm{h}^{-1} \cdot \mathrm{m}^{-2} \cdot \mathrm{bar}^{-1}$ was obtained with a cuttlefish effluent in microfiltration mode. Besides, the regeneration of the membrane can be performed 
using a thermal treatment at $450{ }^{\circ} \mathrm{C}$ during $3 \mathrm{~h}$. Harabi et al. reported the development of supports and MF membranes manufactured from local kaolin and calcium oxide mixtures [84]. The MF layer, deposited on the supports, was obtained by the slip-casting technique using suspensions of anorthite $\left(\mathrm{CaO} \cdot \mathrm{Al}_{2} \mathrm{O}_{3} \cdot 2 \mathrm{SiO}_{2}\right)$ powder. The membrane may be used for MF and also as a support for UF and nanofiltration (NF) membranes.

Ha et al. prepared sintered diatomite supports for microfiltration by using a sacrificial polymer template [85]. The largest pore sizes of the sintered diatomite remained at around $1 \mu \mathrm{m}$. Furthermore, these largest pore sizes of the supports could be controlled by depositing a diatomite separation layer. Findings showed the feasibility of using sintered diatomite as a porous ceramic membrane for microfiltration. Barrouk et al. prepared and characterised low-cost ceramic MF membranes, with tubular configuration based on Moroccan phosphate [86]. The membrane support was prepared by the extrusion of a ceramic paste made with lixiviated phosphate powder. The MF layer made also from the same material was deposited on the support by slip casting. In consequence, this selective layer presents the advantage of having the same composition as that of its support. The membrane displays interesting retention properties regarding the suspended matter, turbidity, total phosphorus, and pathogens. Filtration tests conducted using effluent water produced by the washing phosphate process, suspensions of lime or alumina hydroxide and water wells clearly revealed the performance of the MF membrane elaborated, which was similar to that of a commercial $\alpha$-alumina membrane. Again, the ceramic MF membranes elaborated in this work can also be used as a support for diverse ultrafiltration layers.

As can be deduced from the above, the literature provides abundant evidence of the characteristics of low-cost membranes as well as their potentially good performance in microfiltration and even ultrafiltration applications. Comparison with the characteristics of commercial ceramic membranes based on pure ceramic oxides also allows us to deduce the numerous industrial applications that could be expected. However, in most of the reviewed research, the performance of the membranes developed is based on laboratory or pilot scale tests with relatively short experimental times compared to industrial practice. Consequently, it is necessary to advance in the study of this type of ceramic membranes accessing to a research phase where the designed 
membranes are tested in real environments for enough time to estimate, in a more precise way, the advantages of these new ceramic membranes.

\section{Applications}

The potential applications of low-cost ceramic membranes cover virtually all applications of commercial ceramic membranes obtained with pure oxides. Thus, the range of applications of low-cost ceramic membranes includes oil removal, toxic heavy metal removal, wastewater treatment of various industries, etc. They have also been tested in several production processes, especially in food industry.

\subsection{Food industry: manufacturing processes}

In the processing of fruit juices, ceramic membranes make it possible to obtain high quality, additive-free juices with a fresh, natural taste that lasts during storage. Considering that many varieties of fruit juices are acidic, with $\mathrm{pH}$ between 3 and 5, low-cost ceramic membranes are a good alternative, due to their high chemical and thermal stability (in some varieties of juice high temperatures are used to increase the permeate flow) and their low price. Emani et al. prepared ceramic membranes for filtration of mosambi (sweet lime) juice with mixtures of kaolin, quartz and calcium carbonate by uniaxial pressing [6]. Qin et al. made ceramic membranes using fly ash particles, which were applied in the microfiltration of centrifuged kiwi juice [97].

In the dairy industry, ceramic membranes can be used for both milk pasteurization and whey valorization. The microfiltration of milk has the advantage of reducing the number of bacteria and spores without affecting the taste, extending the life of the milk, compared to other pasteurization processes such as the UHT process. Almandoz et al. used ceramic membranes whose composition was based on a mixture of low-cost raw materials (clay, bentonite, feldspar, quartz and alumina) in the microfiltration of goat milk from local dairy farms [34]. The tests were carried out at a transmembrane pressure of $72 \mathrm{kPa}$ and a temperature of $30{ }^{\circ} \mathrm{C}$, obtaining a high degree of pasteurization of the milk, with high efficiency in bacteria removal, maintaining practically constant the other physicochemical properties of the original milk. On the other hand, the dairy 
industry produces a large amount of whey that can be recovered for use in various industries. It is normally processed for food use in the form of whey powder and other high-quality proteinrich products. In addition, its value increases if it is demineralized, an operation that can be carried out by means of membranes. However, when whey is not valued, especially in emerging countries, it is discharged into rivers near the production site. Over time, the whey acidifies, and bacteria are generated that contaminate the drinking water pumped from the river. In this case, the whey becomes a contaminant of the river, making it impossible to use the water for human consumption. Thus, the use of low-cost ceramic membranes for the recovery of whey has a twofold advantage: increase the profits of the farmer and reduce pollution of river water. To this end, Khider et al. synthesized ceramic membranes based on Algerian clay for use in the treatment of whey from a dairy plant in the region of Boudouaou (Algeria) [30].

Another case described is the refining of raw rice bran oil, which is obtained from the rice husk, and is used in food processing and cosmetics manufacture. This oil is mainly composed of triglycerides; however, it also contains minority compounds, such as phospholipids, $\beta$-carotene, chlorophyll, free fatty acids, particulate matter, sterols, pigments, proteins, etc., which reduce oil quality and processing efficiency. The presence and quantity of these minority compounds depend on the nature and origin of the rice husk. Roy et al. evaluated the pilot-scale efficacy of a lowcost alumina and clay-based membrane to remove polymers, waxes and acids from rice bran oil micelles [98].

\subsection{Food industry: wastewater treatments}

The canning industry of marine products produces a large amount of wastewater, which is generally discharged into the coast and is responsible for a large pollution, increasing the phenomenon of eutrophication (increase of nutrients in fresh water, which causes an excess of phytoplankton (Anon n.d.)) and the proliferation of unwanted algae. As an example, prior to freezing, cuttlefish should be cleaned to remove the black color caused by its ink, generating a highly colored wastewater. Khemakhem et al. developed microfiltration ceramic membranes based on Tunisian clay for the treatment and discoloration of wastewater generated in the cuttlefish conditioning process [31]. 
Slaughterhouse wastewater treatment plants must be designed to reduce the levels of certain parameters, such as chemical oxygen demand (COD), oils and fats, suspended solids, and pathogens, among others. Normally, pretreatment is carried out using grids and collectors to retain solids and grease. Next, a primary treatment is applied to eliminate a significant amount of suspended solids by means of physicochemical processes (addition of flocculants). Finally, the effluent undergoes secondary biological treatment. Almandoz et al. used ceramic membranes based on low-cost compositions (clay, bentonite, feldspar, quartz and alumina) in the microfiltration of the pre-treated effluent from the wastewater of this process, operating at a pressure of $100 \mathrm{kPa}$ and a temperature of $25^{\circ} \mathrm{C}$; obtaining promising results, with a high retention of bacteria and reduction of COD [34].

\subsection{Textile industry: wastewater treatments}

Textile manufacturing processes include the wet chemical processing operations required to prepare, purify, dye or finish the product, which generate wastewater whose pollutant load includes both the impurities of the raw materials used and the remains of the chemical reagents employed during the aforementioned operations. This industry generates high volumes of effluents, with a very variable composition and concentration of contaminants, including COD, biological oxygen demand (BOD), oils and fats, pigments, phenols, heavy metals, etc. Conventional treatment for wastewater from the textile industry mainly includes biological treatment, precipitation, coagulation/flocculation, flotation, oxidation and adsorption. However, the main problem comes from residual pigments, as many are not biodegradable, which makes difficult to treat this wastewaters using conventional systems [99]. Palacio et al. developed membranes from Moroccan clays and phosphates to carry out an initial clarification of wastewater from the Moroccan textile industry, reducing the concentration of pigments such as murexide (ammonium purpurate), methyl orange and potassium chromate [33]. Khemakhem et al. prepared ceramic membranes based on residues from the phosphate industry for the treatment of wastewater from the textile industry, obtaining effluents with reduced turbidity ( $99 \%$ reduction), color (removal greater than 96\%) and COD (90\% decrease) [87]. 
Tannery industry involves the transformation of animal skins into leather, producing both liquid and solid contaminants. The entire tanning process can be divided into 3 main stages: beamhouse (section of the tanning where the skins are prepared for pickling (Anon n.d.)), tanning and finishing. Beamhouse stage generates the greatest volume of wastewater (around 40\%). The effluents from the tanning industry are characterized by high concentrations of pollutants and a wide variety of compositions, such as suspended solids, sulphur and chromium salts, etc. Consequently, physical, physicochemical and biological treatments can be applied. Majouli et al. developed a microfiltration membrane, with cordierite support and selective zirconia layer, for the treatment of wastewater from the preparation stage of the tanning industry [100].

\subsection{Metallurgy industry: chromium plating baths}

Chromium electrolytic coatings are used in industry to protect metals from corrosion, improve their appearance and performance. Chromium coatings are applied for both technical and decorative purposes in numerous industries, in the manufacture of automobiles, household appliances, furniture, taps, electronics, etc.

Chromium plating baths, which consist mainly of concentrated solutions of $\mathrm{Cr}$ (VI) in sulphuric medium, are used to coat objects with metallic chromium by means of electrochemical procedures. With this method, the chromium plating layer is obtained by reducing the $\mathrm{Cr}(\mathrm{VI})$ to $\mathrm{Cr}$ metal on the object to be coated. However, during the process there is also the partial reduction of $\mathrm{Cr}(\mathrm{VI})$ to $\mathrm{Cr}(\mathrm{III})$, which can no longer be reduced to metal under normal operating conditions in chrome plating cells. In consequence, when the concentration of $\mathrm{Cr}(\mathrm{III})$ reaches a certain limit, chrome plating cannot be carried out properly, and the bath is considered to be exhausted. However, these baths still contain a high concentration of $\mathrm{Cr}(\mathrm{VI})$, making them a highly polluting residue, given their very acidic and oxidizing character.

Sánchez et al. developed a ceramic membrane based on a kaolin-alumina mixture for the regeneration of exhausted baths in an electrochemical reactor [101-103]. This membrane separates the two cells of the reactor, allowing the passage of the electric current through the migration of ions, but preventing the diffusion of $\mathrm{Cr}$ (III) and $\mathrm{CrO}_{4}{ }^{2-}$. In this way, $\mathrm{Cr}$ (III) is 
oxidized to $\mathrm{Cr}(\mathrm{VI})$ by an electrochemical procedure, and the membrane prevents the formed $\mathrm{CrO}_{4}^{2-}$ from returning to the exhausted bath cell.

\subsection{Separation of oil-water emulsions}

Oil-water emulsions are one of the major pollutants in aquatic environments. Industries such as metallurgy, petrochemistry, transport, textiles, food, etc., generate wastewater containing oils in concentrations between $50-1000 \mathrm{mg} \cdot \mathrm{L}^{-1}$, which must be treated before discharge, as the maximum allowed concentration is around $10-15 \mathrm{mg} \cdot \mathrm{L}^{-1}$. Among all the available separation technologies, membrane filtration is one of the most promising methods for the separation of water-oil emulsions, due to its advantages: no chemical additives are needed to break the emulsions, it has high efficiency in the elimination of COD and the installations are compact and automated.

To apply filtration through membranes in the separation of oil-water emulsions at an industrial level, ceramic membranes have advantages over polymeric ones, due to their greater stability against polar and chlorinated solvents, extreme $\mathrm{pH}$, high concentrations of oils present in industrial wastewater, as well as their much better thermal and mechanical stability. This has favored the publication of abundant literature related to the separation of these emulsions by means of low-cost ceramic membranes. There are numerous studies from different groups that asses the efficiency of kaolin-based membranes for the separation of oil-water emulsions, analyzing process parameters as well as fouling mechanisms (Vasanth et al. [104,105], Nandi et

al. [106], Eom et al. [107]). In the study by Abbasi et al. the suitability of mullite ceramic membranes for the treatment of oil-water emulsions was analyzed, obtaining promising results [108].

\subsection{Treatment of groundwater and surface water for human consumption}

Several studies have appeared using ceramic filters based on local low-cost raw materials for water purification in areas with scarce economic and water resources. The treated water was intended for human consumption, and the elimination of viruses, bacteria and other microorganisms was carried out through a simple gravitational filtration process [109-111]. One example is the work of Hasan et al., which applied a ceramic membrane based on local clay in a 
membrane biological reactor (MBR) for the removal of arsenic from groundwater in Bangladesh [51]. The iron oxide flocs adsorb the arsenic from the water and are then separated by a low-cost membrane inserted into the MBR.

The use of low-cost ceramic membranes made from waste materials for a membrane biological reactor (MBR) was recently reported as set out above [112]. The ceramic composition was formulated to valorize waste products from different agricultural and industrial processes. Ceramic supports were coated with selective, low-cost ceramic layers as well. An immersed reactor comprising membrane modules with 50 flat hollow membranes was designed as seen in Figure 10A. Water conditioning trials showed good permeability in the industrial assembly (Figure 10B). Moreover, preliminary tests with real wastewater containing between $8-10 \mathrm{~g} \cdot \mathrm{L}^{-1}$ of activated sludge displayed a promising performance of the reactor.

\subsection{Emerging applications}

An incipient application of low-cost ceramic membranes deals with supports for the deposition of active substances, which transform them into basic components for more sophisticated processes than those of the different levels of filtration.

One possible application is ion exchange ceramic membranes, which allow the substitution of organic membranes in the electrodialysis treatment of very acid or corrosive effluents. Ion exchange membranes (cationic and anionic, Figure 13) are the key components of an electrodialysis reactor. Although these membranes are usually organic, they are not compatible with certain effluents (such as residual chromium plating baths, very acidic and oxidizing). Therefore, low-cost ceramic membranes in whose porous network an ion exchanger, also inorganic, has been fixed represent an interesting alternative. In this way, a ceramic microporous support was manufactured from kaolin, alumina and starch by the traditional ceramic method and the ion exchangers were deposited into its porous network. The cation exchanger was hydrated zirconium phosphate [113], and the anion exchanger hydrated zirconium oxide [114], or hydrated cerium dioxide [115], which were deposited as layers of nanometric particles (Figure 14). The electrochemical behavior of the ceramic membranes resembled that of the organic ion-exchanger membranes under certain conditions. 
Another application is to use the low-cost membrane as a support for catalysts, so that the catalytic membrane obtained becomes a component of catalytic reactors. A specific case is the synthesis of membranes for the elimination of nitrate ion in waters from aquifers, the high concentration of which is a public health problem in many areas. Pérez-Fernández et al. developed a catalytic membrane based on a low-cost ceramic support, in whose porous network they deposited Pd and $\mathrm{Cu}$ as catalysts [116]. This membrane allowed the reduction of the nitrate ion to $\mathrm{N}_{2}$, passing through it the water previously saturated with $\mathrm{H}_{2}$. In laboratory conditions, $60 \%$ nitrate conversions were achieved.

Finally, the digital printing revolution has also reached low-cost ceramic membranes. Although it is in the early stages of development, some work has already been done to deposit the intermediate and selective layers using inkjet printing on a low-cost ceramic substrate [117]. The possibility of controlling the type and quantity of material deposited in each point of the surface of the support, will allow in the future to control the microstructure of the different layers, and to include active substances, as catalysts, in specific points of the layers. Therefore, it can be expected that in the coming years the variety of available low-cost ceramic membranes will increase, as well as the range of potential applications for them.

\section{Conclusions}

In recent years, intense research activity has taken place in the field of ceramic membranes with the aim of designing new materials based on ceramic raw materials typical of the most traditional ceramics (silicate ceramics), often incorporating residues in the initial composition. The driving force of this research activity has been the clear possibility of lowering the cost of current ceramic membranes, based on ceramic oxides, maintaining, as far as possible, their performance.

Broadly speaking, regarding the starting compositions employed, there are two main different branches: compositions based on advanced ceramics (e.g. those containing alumina) with potential applications in very aggressive media and compositions exclusively based on traditional ceramics with applications with lower demanding performance. Regardless the branch adopted, clay minerals are commonly used to provide the composition with enough plasticity for the 
subsequent shaping step. Very commonly, pore former materials are indispensable for the ceramic membrane to obtain the necessary pore size and porosity for the intended application. Starch as organic and calcite/dolomite as inorganic represent typical porogen substances but many other raw materials and wastes have been tested. The paper has also discussed the pore formation mechanism attributed to these pore former materials. Basically, a minimum amount of pore former is necessary so as to create an interconnected porosity which enhances membrane permeability.

Membrane fabrication processes for low-cost ceramic membranes follow the same steps and use the same shaping processes as their commercial ceramic membrane counterparts. The most common manufacturing methods are extrusion and pressing, being slip casting, tape casting and freeze casting less frequent. The choice of a given method depends on the application requirements, the intended membrane structure and the available materials. Low-cost ceramic substrates can be used directly as microfiltration membranes. However, selective layers can also be applied to them, which reduce the effective pore size of the membranes and allow them to be used in other separation processes. Dip-coating is the main deposition method for selective layers where conventional compositions are used to follow the low-cost philosophy by means of a higher intensity milling.

Low-cost ceramic membranes generally possess the characteristics of ceramic materials: chemical stability, high mechanical resistance, brittleness, thermal and electrical insulation, etc. Characteristics of commercial and low-cost ceramic membranes display similar variability ranges. Porosities of commercial membranes, $30-40 \%$, are slightly lower than those of low-cost membranes (40-50\%) while water permeability values lie at similar intervals, all below $1000 \mathrm{~L} \cdot \mathrm{h}^{-}$ ${ }^{1} \cdot \mathrm{m}^{-2} \cdot \mathrm{bar}^{-1}$. However, due to the difference in raw materials and manufacturing processes, the properties of low-cost ceramic membranes differ, in some extent, from those of commercial ceramic membranes based on pure oxides.

The potential applications of low-cost ceramic membranes cover virtually all applications of commercial ceramic membranes obtained with pure oxides. Thus, the range of applications of low-cost ceramic membranes includes oil removal, toxic heavy metal removal, wastewater 
treatment of various industries, etc. They have also been tested in several production processes, especially in food industry. However, most of the research is based on laboratory or small pilot plants, therefore much more industrial research is necessary to validate the performance of this new type of membranes in real application environments for long time.

\section{Biblography}

1) Marchese, J. et al. Fabricación y caracterización de membranas cerámicas tubulares para microfiltración. Bol. Soc. Esp. Ceram. Vidr., 39[2] (2000) 215-219.

2) Mulder, M. Basic principles of membrane technology $2^{\text {nd }}$ ed. (1996). Kluwer Academic Publishers, Dordrecht, The Netherlands.

3) Baker, R.W. Membrane technology and applications $2^{\text {nd }}$ ed. (2004), John Wiley \& Sons, Chichester, UK.

4) Mallada, R., Menéndez, M. Inorganic membranes synthesis, characterization and applications $1^{\text {st }}$ ed (2008), Elsevier B.V., Oxford, UK.

5) Burggraaf, A.J., Cot, L. 1996. Fundamentals of Inorganic Membranes, Science and Technology (1996), Elsevier, Amsterdam, The Netherlands.

6) Emani, S., Uppaluri, R. \& Purkait, M.K. Preparation and characterization of low-cost ceramic membranes for mosambi juice clarification. Desalination, 317 (2013) 32-40.

7) Nandi, B.K., Uppaluri, R., Purkait, M.K., 2011. Identification of optimal membrane morphological parameters during microfiltration of mosambi juice using low cost ceramic membranes. LWT - Food Sci. Technol., 44 (2011) 214-223.

8) Vasanth, D., Uppaluri, R., Pugazhenthi, G. Influence of sintering temperature on the properties of porous ceramic support prepared by uniaxial dry compaction method using low-cost raw materials for membrane applications. Sep. Sci. Technol., 46[8] (2011) 12411249. 
9) Monash, P., Pugazhenthi, G. Development of ceramic supports derived from low-cost raw materials for membrane applications and its optimization based on sintering temperature. Int. J. Appl. Ceram. Technol., 8[1] (2011) 227-238.

10) Bhide, B.C., Stern, S. A. A new evaluation of membrane processes for the oxygenenrichment of air. II. Effects of economic parameters and membrane properties. J. Memb. Sci., 62[1] (1991) 37-58.

11) Koros, W.J., Mahajan, R. Pushing the limits on possibilities for large scale gas separation: which strategies? J. Memb. Sci., 175[2] (2000) 181-196.

12) Bose, S., Das, C. Preparation and characterization of low-cost tubular ceramic support membranes using sawdust as a pore-former. Mater. Lett., 110 (2013) 152-155.

13) Harabi, A. et al. A new and economic approach to fabricate resistant porous membrane supports using kaolin and $\mathrm{CaCO}_{3}$. J. Eur. Ceram. Soc., 34[5] (2014) 1329-1340.

14) Bouzerara, F. et al. Porous ceramic supports for membranes prepared from kaolin and dolomite mixtures. J. Eur. Ceram. Soc., 26[9] (2006) 1663-1671.

15) Akhtar, F., Rehman, Y., Bergström, L. A study of the sintering of diatomaceous earth to produce porous ceramic monoliths with bimodal porosity and high strength. Powder Technol., 201[3] (2010) 253-257

16) Bejjaoui, R. et al. Synthesis and characterization of cordierite ceramic from Moroccan stevensite and andalusite. Appl. Clay Sci., 49[3] (2010) 336-340.

17) Dong, Y., Diwu, J., et al. Phase evolution and sintering characteristics of porous mullite ceramics produced from the fly-ash $\mathrm{Al}(\mathrm{OH})_{3}$ coating powders. J. Alloy. Compd., 460[12] (2008) 651-657.

18) Zhou, J. et al., 2010. Elaboration and characterization of tubular macroporous ceramic support for membranes from kaolin and dolomite. J. Porous Mat., 17[1] (2010) 1-9.

19) Weir, M.R., Rutinduka, E., Detellier, C., 2001. Fabrication, characterization and preliminary testing of all-inorganic ultrafiltration membranes composed entirely of a naturally occurring sepiolite clay mineral. J. Memb. Sci., 182 (2001) 41-50. 
20) Dong, Y. et al. Fabrication and characterization of low-cost tubular mineral-based ceramic membranes for micro-filtration from natural zeolite. J. Memb. Sci., 281[1-2] (2006) 592-599.

21) Mao, R.L., et al., 1999. Mechanical and pore characteristics of zeolite composite membranes. J. Mater. Chem., 9[3] (1999) 783-788.

22) Guechi, A. et al. Elaboration and characterization of tubular supports for membranes filtration. Desalin. Water Treat., 57 (2016) 5246-5252.

23) Ghouil, B., Harabi, A., Bouzerara, F. Brihi, N. Elaboration and characterization of ceramic membrane supports from raw materials used in microfiltration. Desalin. Water Treat., 57 (2016) 5241-5245.

24) $\mathrm{Li}$ et al. Modeling of relationship between water permeability and microstructure parameters of ceramic membranes. Desalination 192 (2006) 340-345.

25) Lorente-Ayza, M.M. et al. Influence of starch content on the properties of low-cost microfiltration ceramic membranes. Ceram. Int., 41 (2015) 13064-13073.

26) Lorente-Ayza, M.M. et al. Role of starch characteristics in the properties of low-cost ceramic membranes. J. Eur. Ceram. Soc., 35 (2015) 2333-2341.

27) Lorente-Ayza, M.M. et al. On the underestimated effect of the starch ash on the characteristics of low-cost ceramic membranes. Ceram. Int., 42 (2016) 18944-18954.

28) Harabi, A., Bouzerara, F., Condom, S. Preparation and characterization of tubular membrane supports using centrifugal casting. Desalin. Water Treat., 6[1-3] (2009) 222226.

29) Bouzerara, F. et al. Elaboration and properties of zirconia microfiltration membranes. Procedia Eng., 33 (2012) 278-284.

30) Khider, K., Akretche, D.E., Larbot, A. Purification of water effluent from a milk factory by ultrafiltration using Algerian clay support. Desalination, 167 (2004) 147-151.

31) Khemakhem, S., Ben Amar, R., Larbot, A. Synthesis and characterization of a new inorganic ultrafiltration membrane composed entirely of Tunisian natural illite clay. Desalination, 206[1-3] (2007) 210-214. 
32) Belibi, P. et al. Microfiltration ceramic membranes from local Cameroonian clay applicable to water treatment. Ceram. Int., 41[2] (2015) 2752-2759.

33) Palacio, L. et al. Ceramic membranes from Moroccan natural clay and phosphate for industrial water treatment. Desalination, 245[1-3] (2009) 501-507.

34) Almandoz, M. et al. Composite ceramic membranes from natural aluminosilicates for microfiltration applications. Ceram. Int., 41[4] (2015) 5621-5633.

35) Fakhfakh, S., Baklouti, S., Bouaziz, J. Elaboration and characterization of low cost ceramic support membrane. Adv. Appl. Ceram., 109[1] (2010) 31-38.

36) Fatimah, I. et al. Ceramic membrane based on $\mathrm{TiO}_{2}$-modified kaolinite as a low cost material for water filtration. Appl. Clay Sci., 118 (2015) 207-211.

37) Belouatek, A. et al. Preparation of inorganic supports for liquid waste treatment. Micropor. Mesopor. Mat., 85[1-2] (2005) 163-168.

38) Potdar, A., Shukla, A., Kumar, A. Effect of gas phase modification of analcime zeolite composite membrane on separation of surfactant by ultrafiltration. J. Memb. Sci., 210 (2002) 209-225.

39) Dong, Y., Feng, X., et al. Preparation of low-cost mullite ceramics from natural bauxite and industrial waste fly ash. J. Alloy. Compd., 460[1-2] (2008) 599-606.

40) Mohammadi, T. et al. Experimental design in mullite microfilter preparation. Desalination, 184[1-3] (2005) 57-64.

41) Saffaj, N. et al. Elaboration and characterization of microfiltration and ultrafiltration membranes deposited on raw support prepared from natural Moroccan clay: application to filtration of solution containing dyes and salts. Appl. Clay Sci., 31 (2006) 110-119.

42) Lorente-Ayza, M.M. Membranas cerámicas de bajo coste para el tratamiento de aguas residuales. Ph.D Thesis. Universitat Jaume I. Castellón (Spain) 80-86.

43) Chevalier, E. et al. Fabrication of porous substrates: a review of processes using pore forming agents in the biomaterial field. J. Pharm. Sci., 97[3] (2008) 1135-1154. 
44) Vijayan, S., Narasimman, R., Prabhakaran, K. A urea crystal templating method for the preparation of porous alumina ceramics with the aligned pores. J. Eur. Ceram. Soc., 33[10] (2013), pp.1929-1934.

45) Gregorová, E., Pabst, W., Bohačenko, I. Characterization of different starch types for their application in ceramic processing. J. Eur. Ceram. Soc., 26[8] (2006) 1301-1309.

46) Gregorová, E. et al. Porous alumina ceramics prepared with wheat flour. J. Eur. Ceram. Soc., 30[14] (2010) 2871-2880.

47) Zeng, T. et al. Processing and piezoelectric properties of porous PZT ceramics. Ceram. Int., 33[3] (2007) 395-399.

48) Efavi, J.K. et al. Development of porous ceramic bodies from kaolin deposits for industrial applications. Appl. Clay Sci., 65-66 (2012) 31-36.

49) Das, B., Chakrabarty, B., Barkakati, P. Preparation and characterization of novel ceramic membranes for micro-filtration applications. Ceram. Int., 42[13] (2016) 14326-14333.

50) Gregorová, E., Pabst, W., b. Porous ceramics prepared using poppy seed as a poreforming agent. Ceram. Int., 33[7] (2007) 1385-1388.

51) Hasan, M.M., Azam, M.S., Nakajima, J. Application of a simple ceramic filter to membrane bioreactor. Desalination, 276[1-3] (2011) 272-277.

52) Bose, S., Das, C. Role of binder and preparation pressure in tubular ceramic membrane processing: design and optimization study using response surface methodology (RSM). Ind. Eng. Chem. Res., 53[31] (2014) 12319-12329.

53) Sánchez, E. et al. Ecological low-cost ceramic membranes based on olive stones as pore former. Euromembrane2018. July 9-12. Valencia (Spain). Book of abstracts. 322-323.

54) Yang, G.C.C., Tsai, C.-M. Effects of starch addition on characteristics of tubular porous ceramic membrane substrates. Desalination, 233[1-3] (2008) 129-136.

55) Bazin, M.M. et al. Effect of starch addition on microstructure and strength of ball clay membrane. Jurnal Teknologi (Sciences and Engineering), 69[9] (2014) 117-120. 
56) Obada, D.O. et al. Physico-mechanical and gas permeability characteristics of kaolin based ceramic membranes prepared with a new pore-forming agent. Appl. Clay Sci., 150 (2017) 175-183.

57) Barba, A. et al. Materias primas para la fabricación de soportes de baldosas cerámicas $2^{\text {nd }}$ ed. (2000) Instituto de Tecnología Cerámica, Castellón (Spain).

58) Beltrán, V. et al. Materias primas empleadas en la fabricación de baldosas de pasta blanca en España. Técnica Cerámica, 241 (1996) 114-128.

59) García-Ten, J. et al. Composiciones para la fabricación de baldosas cerámicas. Influencia de los distintos componentes sobre su comportamiento en el proceso de fabricación. Cerámica Información, 243 (1998) 37-43.

60) Falamaki, C., Naimi, M., Aghaie, A. Dual behavior of $\mathrm{CaCO}_{3}$ as a porosifier and sintering aid in the manufacture of alumina membrane/catalyst supports. J. Eur. Ceram. Soc., 24[10-11] (2004) 3195-3201.

61) Boudaira, B. et al. Preparation and characterization of membrane supports for microfiltration and ultrafiltration using kaolin (DD2) and $\mathrm{CaCO}_{3}$. Desalin. Water Treat., 57[12] (2016) 5258-5265.

62) Carretero, M. et al. The influence of shaping and firing technology on ceramic properties of calcareous and non-calcareous illitic-chloritic clays. Appl. Clay Sci., 20[6] (2002) 301-306.

63) Reed, J.S. Principles of ceramics processing $2^{\text {nd }}$ ed. (1995) John Wiley and Sons, New York, USA.

64) Krakowiak, K.J., Lourenço, P.B., Ulm, F.J. Multitechnique investigation of extruded clay brick microstructure. J. Am. Ceram. Soc., 94[9] (2011) 3012-3022.

65) Lorente-Ayza, M.M. et al. Comparison of extruded and pressed low cost ceramic supports for microfiltration membranes. J. Eur. Ceram. Soc., 35 (2015) 3681-3691.

66) Benito, J.M., Conesa, A., Rodriguez, M.A. Membranas cerámicas. Tipos, métodos de obtención y caracterización. Bol. Soc. Esp. Ceram. Vidr., 43[5] (2004) 829-842. 
67) Monash, P., Pugazhenthi, G., Saravanan, P. Various fabrication methods of porous ceramic supports for membrane applications. Rev. Chem. Eng., 29[5] (2013) 357-383.

68) Nandi, B.K., Uppaluri, R., Purkait, M.K. Preparation and characterization of low cost ceramic membranes for micro-filtration applications. Appl. Clay Sci., 42[1-2] (2008) $102-110$.

69) Hubadillah, S.K. et al. Effect of kaolin particle size and loading on the characteristics of kaolin ceramic support prepared via phase inversion technique. J. As. Ceram. Soc., 4[2] (2016) 164-177.

70) Falamaki, C., Afarani, M.S., Aghaie, A. Initial sintering stage pore growth mechanism applied to the manufacture of ceramic membrane supports. J. Eur. Ceram. Soc., 24[8] (2004) 2285-2292.

71) Ghouil, B., Harabi, A., Bouzerara, F., Boudaira, B., et al. Development and characterization of tubular composite ceramic membranes using natural alumino-silicates for microfiltration applications. Mater. Charac., 103 (2015) 18-27.

72) Janaína A. et al. Microstructural investigation and performance evaluation of slip-cast alumina supports. Ceram. Int., 43 (2017) 3824-3830

73) Xie, L., Yao, D., Xia, Y., Yin, J., Liang, H., Zuo, K., Zeng, Y. High porosity Ca- $\alpha-$ SiAlON ceramics with rod-like grains fabricated by freeze casting and pressureless sintering. J. Eur. Ceram. Soc., 39 (2019) 2036-2041.

74) Zhao, J., Li, Y., Wu, Y., Lv, S., Lu, K. Microstructure of $\mathrm{TiO}_{2}$ porous ceramics by freeze casting of nanoparticle suspensions. Ceram. Int., 43 (2017) 14593-14598

75) Nishihora, R.K., Rachadel, P.R., Quadri, M.A.N, Hotza, D. Manufacturing porous ceramic materials by tape casting_A review. J. Eur. Ceram. Soc., 38 (2018) 988-1001.

76) Ahmad, N., Zaidan, N. Effect of sintering temperature on membrane properties of Sayong ball clay. Appl. Mech. Mater., 315 (2013) pp.349-353.

77) Palacio, L. et al. Fouling, structure and charges of a composite inorganic microfiltration membrane. Colloids Surf. A., 138[2-3] (1998) 291-299. 
78) Saffaj, N. et al. Preparation and characterization of ultrafiltration membranes for toxic removal from wastewater. Desalination, 168 (2004) 259-263.

79) Benito, J.M. et al. Preparation and characterization of tubular ceramic membranes for treatment of oil emulsions. J. Eur. Ceram. Soc., 25[11] (2005) 1895-1903.

80) Kazemimoghadam, M., Mohammadi, T. Synthesis of MFI zeolite membranes for water desalination. Desalination, 206[1-3] (2007) 547-553.

81) Khemakhem, S., Larbot, A., Ben Amar, R. Study of performances of ceramic microfiltration membrane from Tunisian clay applied to cuttlefish effluents treatment. Desalination, 200[1-3] (2006) 307-309.

82) Khemakhem, S. et al. New ceramic membranes for tangential waste-water filtration. Desalination, 167 (2004) 19-22.

83) Masmoudi, S. et al. Elaboration of inorganic microfiltration membranes with hydroxyapatite applied to the treatment of wastewater from sea product industry. $J$. Memb. Sci., 247[1-2] (2005) 1-9.

84) Harabi, A., Guechi, A., Condom, S. Production of supports and filtration membranes from Algerian kaolin and limestone. Procedia Eng., 33 (2012) 220-224.

85) Ha, J.H., Oh, E., Song, I.H. The fabrication and characterization of sintered diatomite for potential microfiltration applications. Ceram. Int., 39[7] (2013) 7641-7648.

86) Barrouk, I. et al. New ceramic membranes from natural Moroccan phosphate for microfiltration application. Desalin. Water Treat., 55[1] (2014) 53-60.

87) Khemakhem, M. et al. Development of an asymmetric ultrafiltration membrane based on phosphates industry sub-products. Ceram. Int., 41[9] (2015) 10343-10348.

88) Li, K. Ceramic membranes for separation and reaction (2007) John Wiley and Sons, Hoboken (NJ) USA.

89) Rawat, M., Bulasara, V.K. Synthesis and characterization of low-cost ceramic membranes from fly ash and kaolin for humic acid separation. Korean J. Chem. Eng., 35 (2018) 725-733. 
90) Saja, S. et al. Elaboration and characterization of a low-cost ceramic membrane made from natural Moroccan perlite for treatment of industrial wastewater. J. Environ. Chem. Eng., 6 (2018) 451-458.

91) Issaoui, M. Limousy, L., Lebeau, B., Bouaziz, J. Fourati, M. Manufacture and optimization of low-cost tubular ceramic supports for membrane filtration: application to algal solution concentration. Environ. Sci. Pollut. R., 24 (2017) 9914-9926.

92) Almandoz, M.C., Marchese, J., Prádanos, P., Palacio, L., Hernández, A. Preparation and characterization of non-supported microfiltration membranes from aluminosilicates. $J$. Memb. Sci. 24 (2004) 95-103.

93) Hedfi, I., Hamdi, N., Rodriguez, M.A., Srasra, E., Development of a low cost microporous ceramic membrane from kaolin and Alumina, using the lignite as porogen agent, Ceram. Int. 42 (2016) 5089-5093.

94) Dong, Y., Liu, X., Ma, Q., Meng, G. Preparation of cordierite-based porous ceramic micro-filtration membranes using waste fly ash as the main raw materials, J. Memb. Sci. 285 (2006) 173-181.

95) Bouzerara, F., Boulanacer, S., Harabi, A. Shaping of microfiltration (MF) $\mathrm{ZrO}_{2}$ membranes using a centrifugal casting method. Ceram. Int. 41 (2015) 5159-5163.

96) Dong, Y., Feng, X., Dong, D., Wang, S., Yang, J., Gao, J., Liu, X., Meng, G. Elaboration and chemical corrosion resistance of tubular macro-porous cordierite ceramic membrane supports, J. Memb. Sci. 304 (2007) 65-75.

97) Qin, G. et al. Microfiltration of kiwifruit juice and fouling mechanism using fly-ash-based ceramic membranes. Food Bioprod. Process., 96 (2015) 278-284.

98) Roy, B. et al. Degumming, dewaxing and deacidification of rice bran oil-hexane miscella using ceramic membrane: Pilot plant study. J. Am. Oil Chem. Soc., 91[8] (2014) 14531460.

99) Judd, S., Jefferson, B. Membranes for industrial wastewater recovery and re-use. (2003) Elsevier Ltd., Oxford, UK. 
100) Majouli, A. et al. Treatment of effluents coming from beamhouse section of tannery by microfiltration through Cordierite/Zirconia and Alumina tubular ceramic. J. Mater. Environ. Sci., 3[5] (2012) 808-815.

101) Sánchez, E. et al. Ceramic membranes for continuous regeneration of spent chromium plating baths. Key Eng. Mater., 264-268 (2004) 2211-2214.

102) Sánchez, E. et al. Síntesis de membranas cerámicas para la regeneración de baños de cromado agotados. Bol. Soc. Esp. Ceram. Vidr., 44[6] (2005) 409-414.

103) Sánchez, E. et al. Membrane electrochemical reactor for continuous regeneration of spent chromium plating baths. Desalination, 200[1-3] (2006) 668-670.

104) Vasanth, D., Pugazhenthi, G., Uppaluri, R. Fabrication and properties of low cost ceramic microfiltration membranes for separation of oil and bacteria from its solution. $J$. Memb. Sci., 379[1-2] (2011) 154-163.

105) Vasanth, D., Pugazhenthi, G., Uppaluri, R. Cross-flow microfiltration of oil-in-water emulsions using low cost ceramic membranes. Desalination, 320 (2013) 86-95.

106) Nandi, B.K. et al. Treatment of oily wastewater using low cost ceramic membrane: Comparative assessment of pore blocking and artificial neural network models. Chem. Eng. Res. Des., 88[7] (2010) 881-892.

107) Eom, J.H. et al. Low-cost clay-based membranes for oily wastewater treatment. $J$. Ceram. Soc. Jpn., 122[1429] (2014) 788-794.

108) Abbasi, M. et al. Oily wastewater treatment using mullite ceramic membrane. Desalin. Water Treat., 37[1-3] (2012) 21-30.

109) Brown, J., Sobsey, M. Microbiological effectiveness of locally produced ceramic filters for drinking water treatment in Cambodia. J. Water Health, 8[1] (2010) 1-10.

110) Salsali, H., McBean, E., Brunsting, J. Virus removal efficiency of Cambodian ceramic pot water purifiers. J. Water Health, 9[2] (2011) 306-311.

111) Simonis, J.J. \& Basson, A.K. Manufacturing a low-cost ceramic water filter and filter system for the elimination of common pathogenic bacteria. Phys. Chem. Earth, Parts $A / B / C, 50-52$ (2012) 269-276. 
112) Zuriaga-Agustí, E. et al. Eco-friendly ceramic membranes for water reuse in membrane bioreactor (MBR). Euromembrane2018. July 9-12. Valencia (Spain). Book of abstracts. 548-549.

113) Martí-Calatayud, M.C. et al. Synthesis and electrochemical behavior of ceramic cation-exchange membranes based on zirconium phosphate. Ceram. Int., 39 (2013) $4045-4054$.

114) Martí-Calatayud, M.C. et al. Ceramic anion-exchange membranes based on microporous supports infiltrated with hydrated zirconium dioxide. RSC Advances, 5 (2015) 46348-46358.

115) Mora-Gómez, J. et al. Anion transport through ceramic electrodialysis membranes made with hydrated cerium dioxide. J. Am. Ceram. Soc., 100 (2017) 4180-4189.

116) Pérez-Fernández, O. et al. Catalytic membrane reactors for nitrate removal using low-cost ceramic supports. IX Iberoamerican congress on membrane science and technology. May. 22-28, 2014, Santander (Spain). Book of abstracts, 253-254.

117) Palacios, M.D. et al. Ink-jet technology applied to engineer low-cost ceramic membranes. Euromembrane2018. July 9-12. Valencia (Spain). Book of abstracts. 126127. 
Table 1 Common configurations in porous ceramic membranes for different applications.

\begin{tabular}{cccc}
\hline Application & Configuration & $\begin{array}{c}\text { Pore diameter } \\
(\mathbf{n m})\end{array}$ & $\begin{array}{c}\text { Selective } \\
\text { layer }\end{array}$ \\
\hline \multirow{2}{*}{ Microfiltration } & 1 layer & 5000 & Macroporous \\
& 2 layers & 250 & Macroporous \\
& 3 layers & 100 & Macroporous \\
\hline Ultrafiltration & 4 layers & 5 & Mesoporous \\
\hline Nanofiltration/Gas & 5 layers & 1 & Microporous \\
\hline separation/Pervaporation & & & \\
\hline
\end{tabular}

Table 2. Precursors to be used as a function of the desired filtration range.

\begin{tabular}{ccc}
\hline Filtration mode & Pore size $(\mathbf{n m})$ & Precursor material \\
\hline Microfiltration & $>60$ & Particle suspension \\
\hline \multirow{2}{*}{ Ultrafiltration } & $20-50$ & Particle suspension \\
& $3-20$ & Colloidal sol \\
\hline Nanofiltration & $<2$ & Polymeric sol \\
\hline
\end{tabular}

Table 3: Compositions mainly based on clays.

\begin{tabular}{ccccc}
\hline $\begin{array}{c}\text { Particle size } \\
(\mu \mathrm{m})\end{array}$ & $\begin{array}{c}\text { Other raw } \\
\text { materials }\end{array}$ & Pore former & Origin & Ref. \\
\hline-- & -- & $\begin{array}{c}\mathrm{CaCO}_{3}(21 \%) ; \\
\text { Starch }(2-10 \%)\end{array}$ & Algeria & {$[23,29,30]$} \\
\hline-- & -- & Tunisia & {$[31]$} \\
\hline $0.3-30$ & -- & Sawdust $(25 \%)$ & $\begin{array}{c}\text { Cameroon } \\
\text { (Adamawa) }\end{array}$ & {$[32]$} \\
\hline-- & Phosphates & Starch $(5-35 \%)$ & Morocco & {$[33]$} \\
\hline $0.2-50$ & $\begin{array}{c}\text { Bentonite; } \\
\text { Alumina; } \\
\text { Quartz; } \\
\text { Feldspar }\end{array}$ & $\mathrm{CaCO}_{3}(10-17 \%)$ & $\begin{array}{c}\text { Argentina } \\
\text { (Piedra Grande) }\end{array}$ & {$[34]$} \\
\hline
\end{tabular}


Table 4: Compositions based on kaolin-clay mixtures.

\begin{tabular}{cccccc}
\hline $\begin{array}{c}\text { Main raw } \\
\text { materials }\end{array}$ & $\begin{array}{c}\text { Particle } \\
\text { size }(\boldsymbol{\mu m})\end{array}$ & $\begin{array}{c}\text { Other raw } \\
\text { materials }\end{array}$ & Pore former & Origin & Ref. \\
\hline $\begin{array}{c}\text { Kaolin }(9 \%) \\
\text { Clay }(82 \%)\end{array}$ & $0.2-70$ & -- & $\begin{array}{c}\text { Corn starch } \\
(9 \%)\end{array}$ & $\begin{array}{c}\text { Tunisia } \\
\text { (Oueslatia) })\end{array}$ & {$[35]$} \\
\hline $\begin{array}{c}\text { Kaolinite }(56-59 \%) \\
\text { Clay }(37 \%)\end{array}$ & -- & -- & $\begin{array}{c}\text { Sawdust } \\
(2.5 \%)\end{array}$ & $\begin{array}{c}\text { Indonesia } \\
\text { (Sukabumi) }\end{array}$ & {$[36]$} \\
\hline $\begin{array}{c}\text { Kaolin } \\
\text { Clay }\end{array}$ & $1-40$ & $\begin{array}{c}\text { Feldspar } \\
\text { Sand }\end{array}$ & $\begin{array}{c}\text { Active coal } \\
(1 \%)\end{array}$ & $\begin{array}{c}\text { Algeria } \\
(\text { Ghazaouet })\end{array}$ & {$[37]$} \\
\hline $\begin{array}{c}\text { Kaolin }(10-15 \%) \\
\text { Clay (13-18\%) }\end{array}$ & $5-10$ & $\begin{array}{c}\text { Feldspar } \\
\text { Quartz } \\
\text { Pyrophyllite }\end{array}$ & $\begin{array}{c}\text { CaCO } \\
(17-23 \%)\end{array}$ & India & {$[9,38]$} \\
\hline
\end{tabular}


Table 5: Membranes based on kaolin and/or clay and formed by pressing.

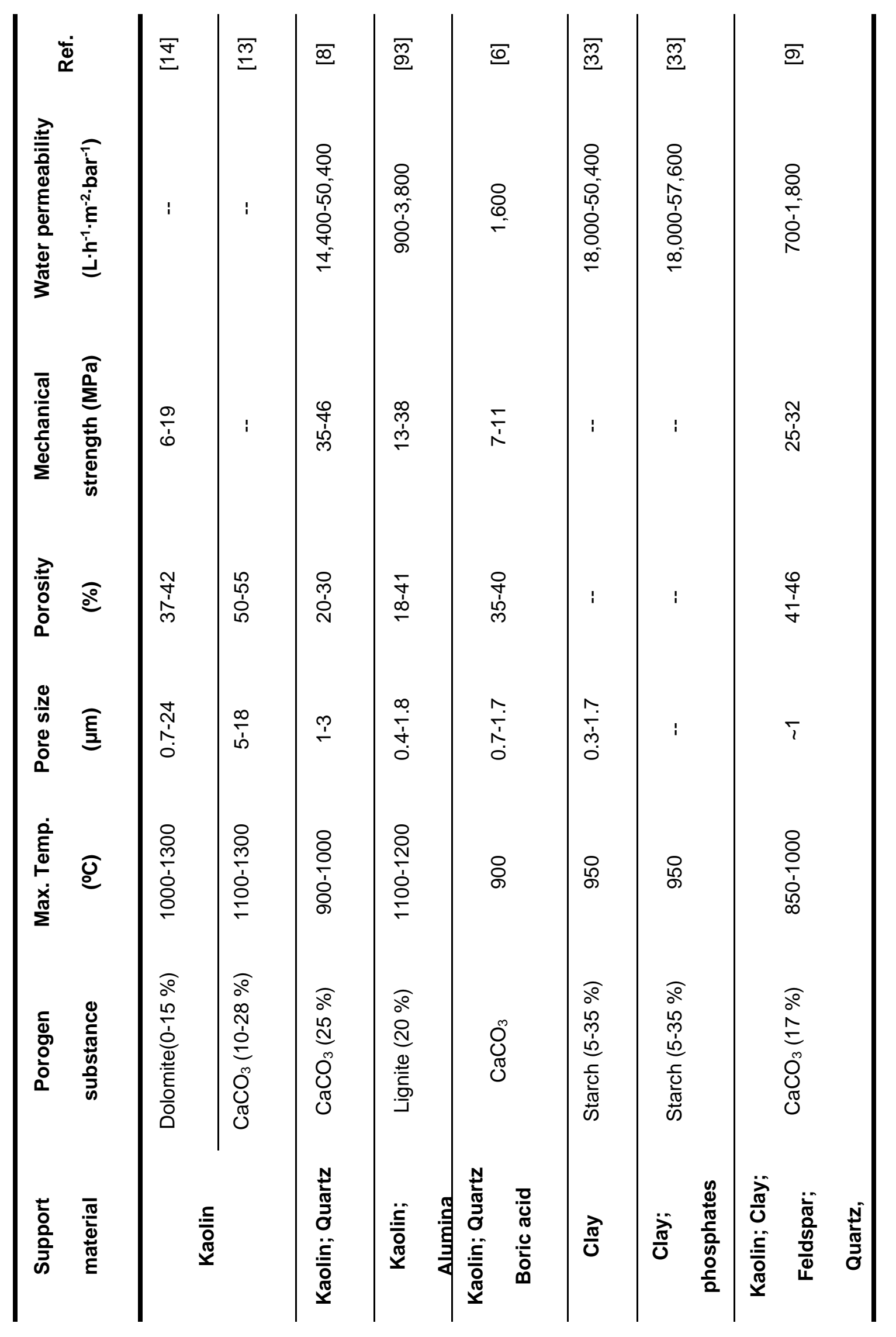


Table 6: Membranes based on kaolin and/or clay and formed by extrusión.

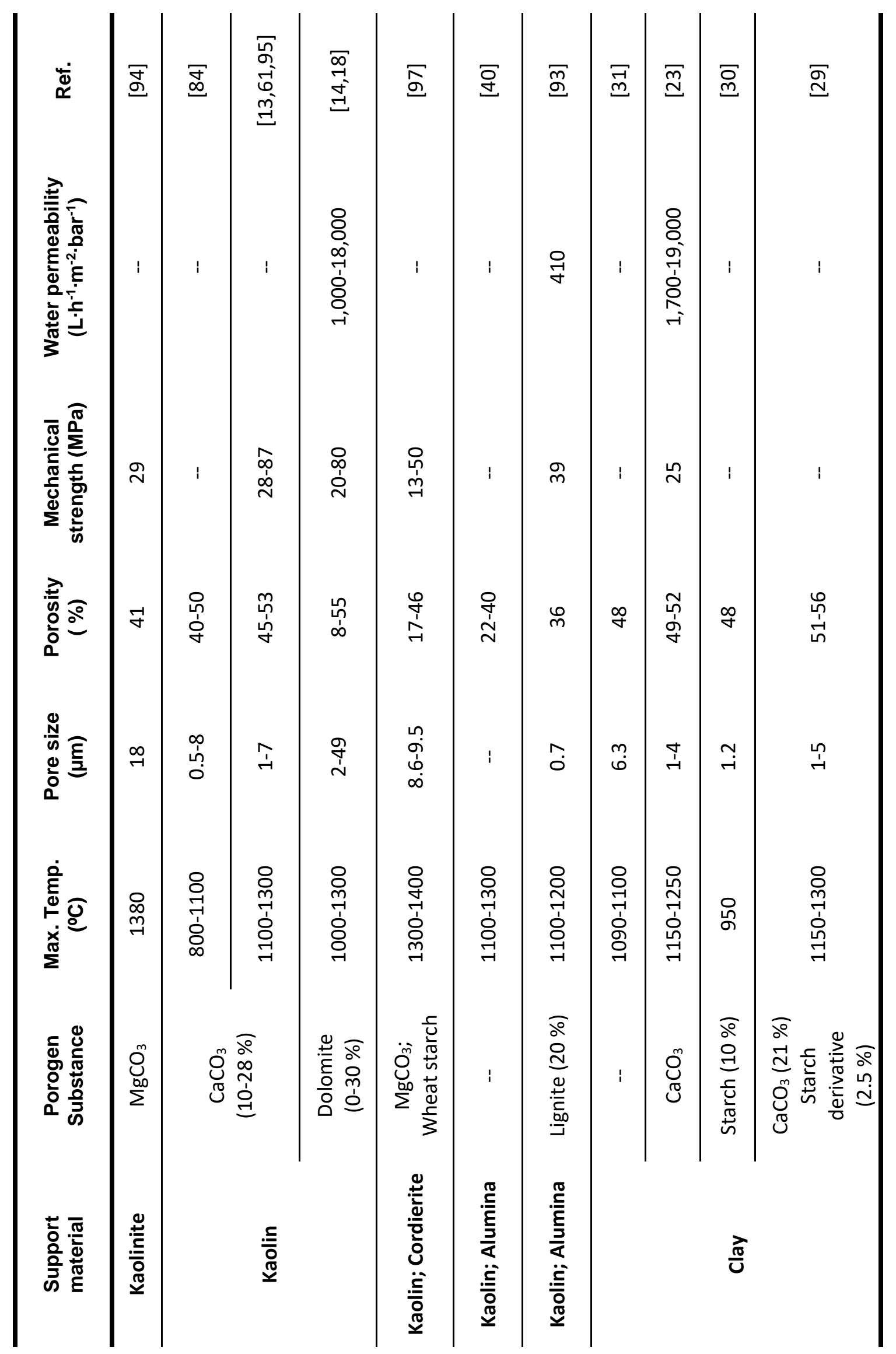


Table 7: Properties of ceramic membranes based on pure oxides (commercial membranes).

\begin{tabular}{|c|c|c|c|c|}
\hline $\begin{array}{l}\text { Industrial } \\
\text { membrane }\end{array}$ & $\begin{array}{l}\text { Pore } \\
\text { size } \\
(\mu \mathrm{m})\end{array}$ & $\begin{array}{l}\text { Porosity } \\
\text { (\%) }\end{array}$ & $\begin{array}{c}\text { Water } \\
\text { permeability } \\
\left(\mathrm{L} \cdot \mathrm{h}^{-1} \cdot \mathrm{m}^{-2} \cdot \mathrm{bar}^{-1}\right)\end{array}$ & Ref. \\
\hline Jiawu High-Tech Co. & $0.2-0.5$ & -- & $523-891$ & \\
\hline Carbosep & 0.45 & -- & 177 & {$[34]$} \\
\hline CeRAM Tami Industries & 0.1 & -- & 342 & \\
\hline \multirow{2}{*}{$\begin{array}{c}\text { a-alumina } \\
\text { (different suppliers) }\end{array}$} & $0.1-0.5$ & 40 & -- & \\
\hline & $1-10$ & $30-40$ & -- & \\
\hline $\begin{array}{c}\text { a-alumina } \\
\text { (Netzsch and Membralox) }\end{array}$ & $0.01-0.05$ & -- & -- & {$[67]$} \\
\hline Y-alumina (US Filters) & 0.005 & -- & & \\
\hline Titania (TAMI industries) & 1.7 & 32 & -- & \\
\hline
\end{tabular}

Table 8: Properties of selective ceramic membranes based on low-cost raw materials

\begin{tabular}{|c|c|c|c|c|c|}
\hline Material & $\begin{array}{c}\text { Max. } \\
\text { temperature } \\
\left({ }^{\circ} \mathrm{C}\right)\end{array}$ & $\begin{array}{l}\text { Dwell } \\
\text { time } \\
\text { (h) }\end{array}$ & $\begin{array}{l}\text { Pore } \\
\text { size } \\
(\mu \mathrm{m})\end{array}$ & $\begin{array}{c}\text { Water } \\
\text { permeability } \\
\left(\mathrm{L} \cdot \mathrm{h}^{-1} \cdot \mathrm{m}^{-2} \cdot \text { bar }^{-1}\right)\end{array}$ & Ref. \\
\hline Lime loams & 1000 & 2 & 0.4 & 870 & [82] \\
\hline Apatite & 600 & 3 & 0.5 & -- & [83] \\
\hline Tunisia clay & 900 & 2 & 0.18 & -- & {$[31,81]$} \\
\hline Illite & 800 & 2 & 0.015 & 88 & [31] \\
\hline Anortite & 850 & 2 & 0.5 & -- & [84] \\
\hline Diatomaceous earth & 1200 & 1 & -- & -- & [85] \\
\hline Algerian kaolin & $1050-1150$ & 1 & 0.2 & 550 & {$[71]$} \\
\hline Phosphate & 800 & 2 & 0.35 & 700 & {$[86]$} \\
\hline $\begin{array}{l}\text { Clay; Bentonite; } \\
\text { Alumina; Quartz }\end{array}$ & 1200 & 0.5 & $0.09-0.55$ & $500-1000$ & [34] \\
\hline
\end{tabular}




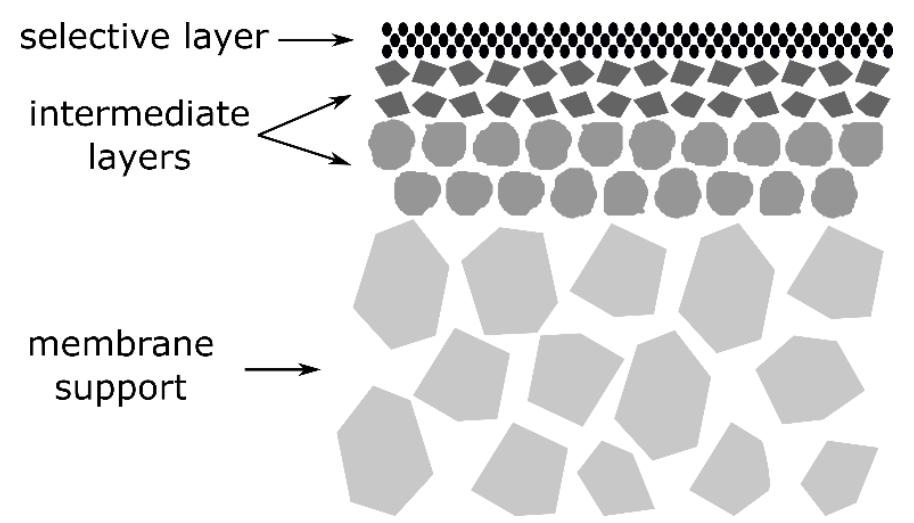

Figure 1: Diagram of an asymmetric membrane.

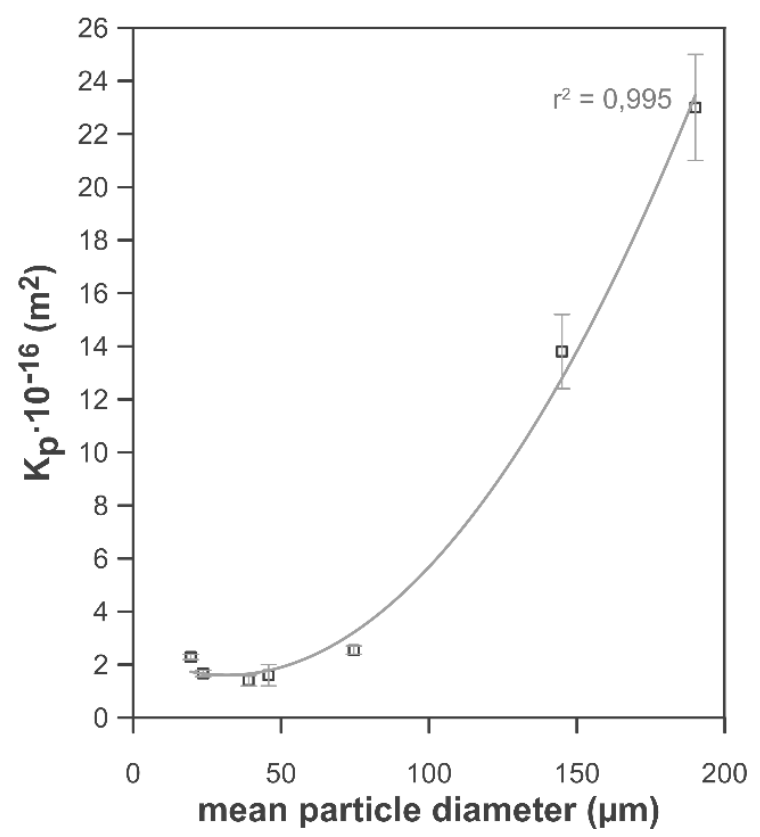

Figure 2: Relation between the water permeability $\left(K_{p}\right)$ of a clay-based low-cost ceramic membrane and the mean particle diameter of used starch (data from [26]). 


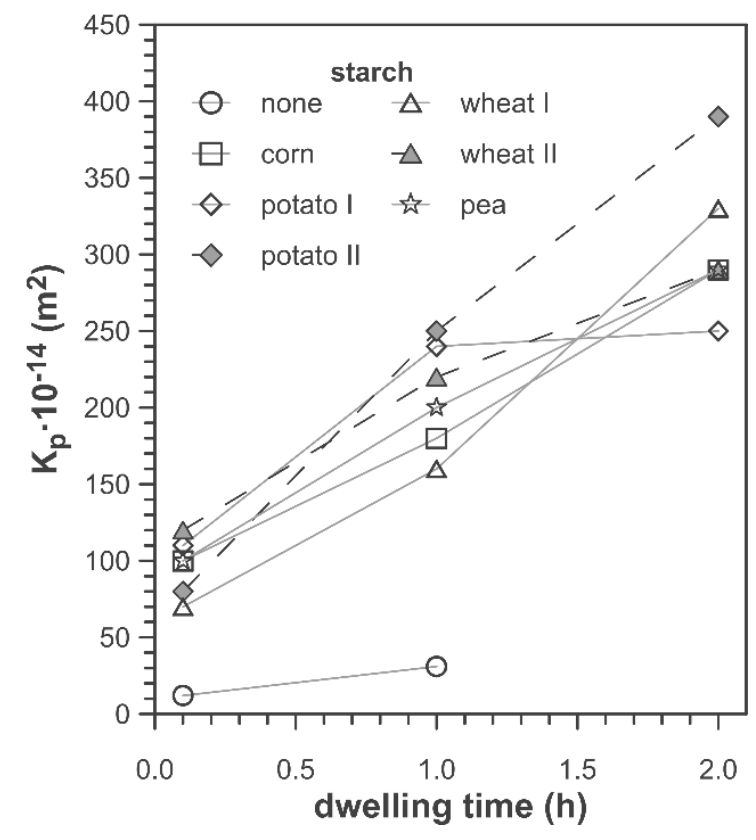

Figure 3: Variation of air permeability $\left(K_{p}\right)$ with sintering (dwelling) time for a clay-based low-cost ceramic membrane composition prepared from the same amount of starch but of different nature (corn, potatoes, wheats and pea) (data from [27]).
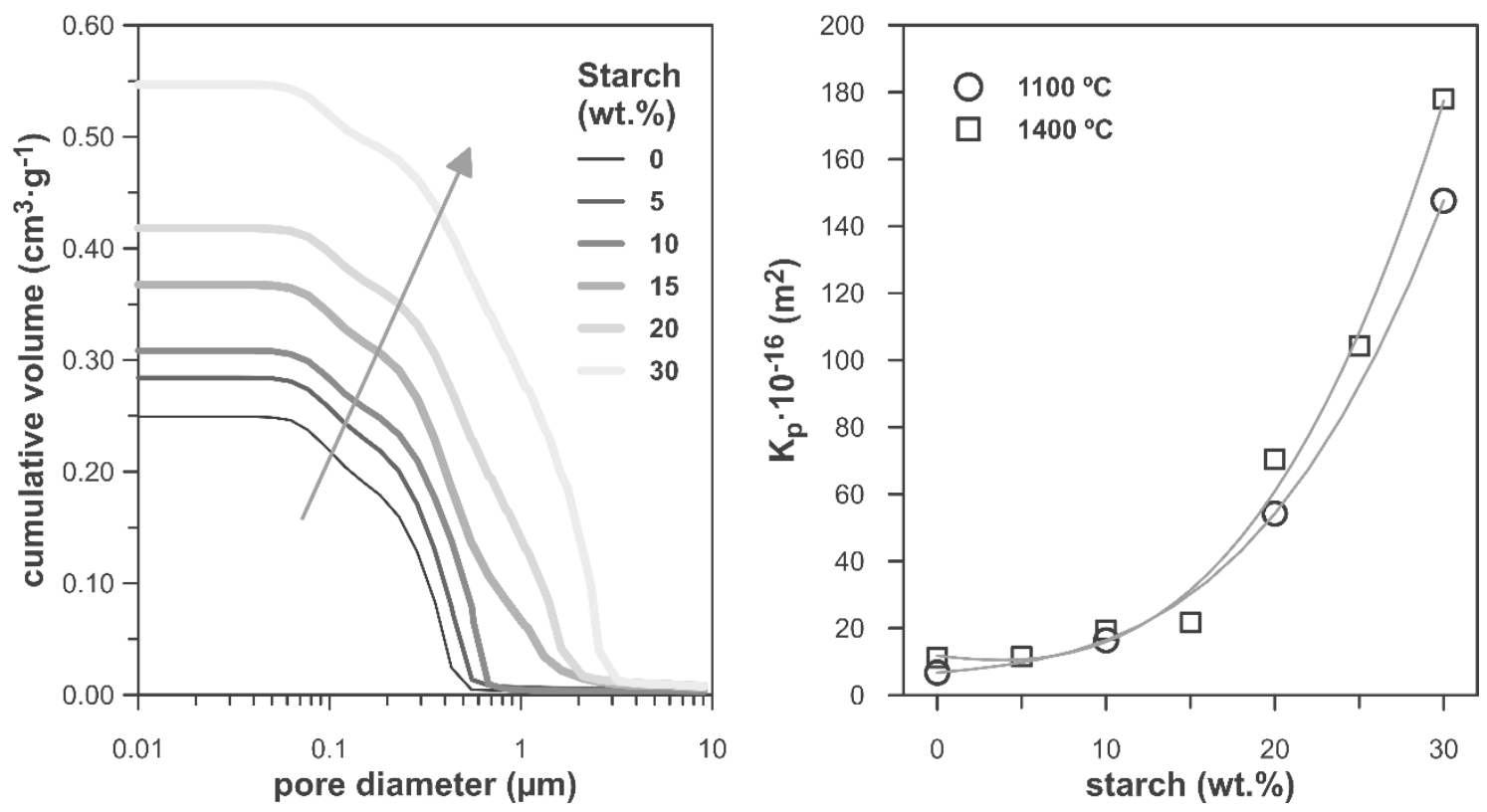

Figure 4: Effect of the amount of starch content in a kaolin-alumina based low-cost ceramic composition on a) accumulate pore size distribution of membranes sintered at $1400{ }^{\circ} \mathrm{C}$ and $\left.\mathrm{b}\right)$ air permeability $\left(\mathrm{K}_{\mathrm{p}}\right)$ of the membranes sintered at $1100{ }^{\circ} \mathrm{C}$ and $1400{ }^{\circ} \mathrm{C}$ (data from [25]). 


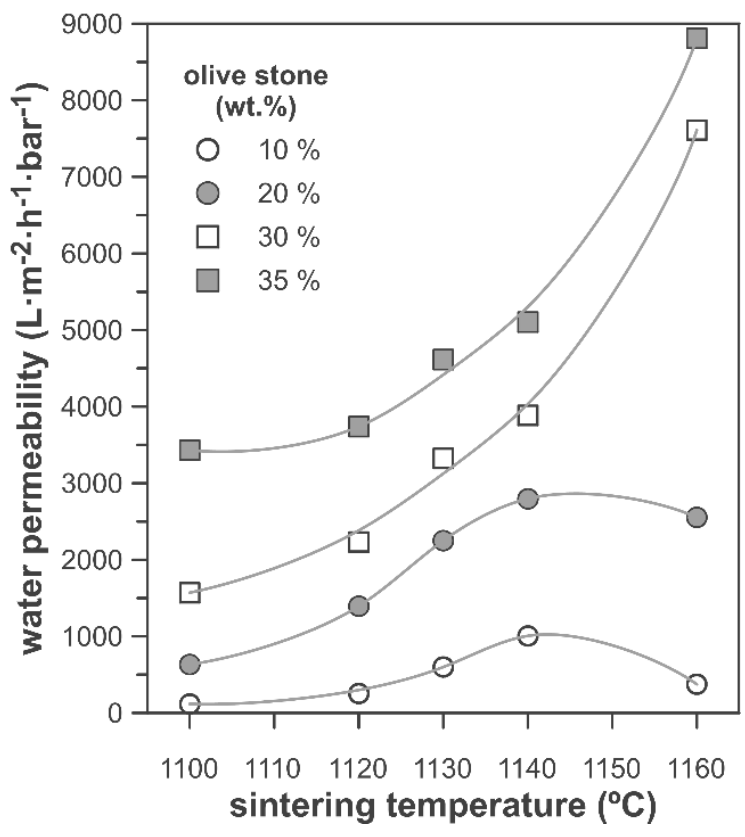

Figure 5: Influence of olive stone content and sintering temperature on water permeability of low-cost ceramic membrane containing olive stone as pore former (data from [53]) 

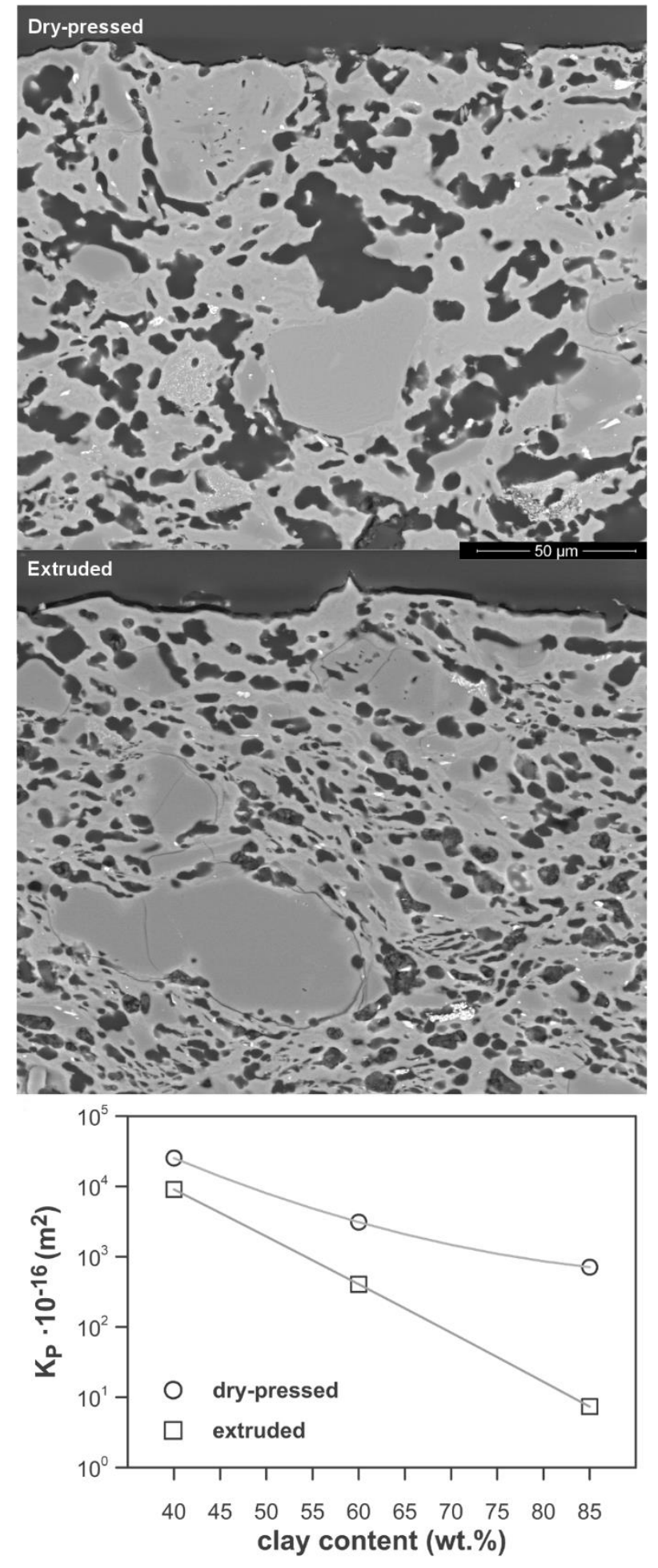

Figure 6: Effect of the shaping method (pressing and extrusion) in clay-based, low-cost ceramic compositions containing three different amounts of clay: 40, 60 and 85 wt.\%. a) micrographs of pressed and extruded sintered specimens with 85 wt.\% of clay content and b) variation of air permeability $\left(K_{p}\right)$ for the pressed and extruded sintered specimens of the three compositions (data from [65]). 


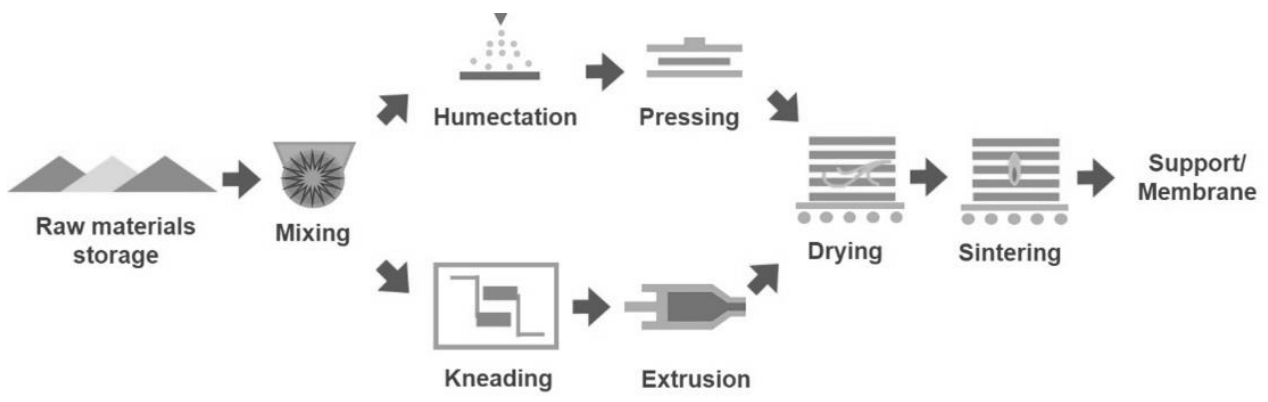

Figure 7: Processes for obtaining low-cost ceramic membranes.

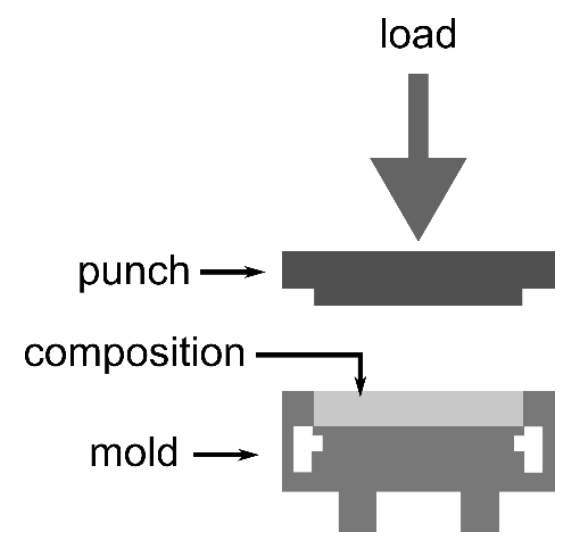

Figure 8: Scheme of uniaxial pressing shaping.

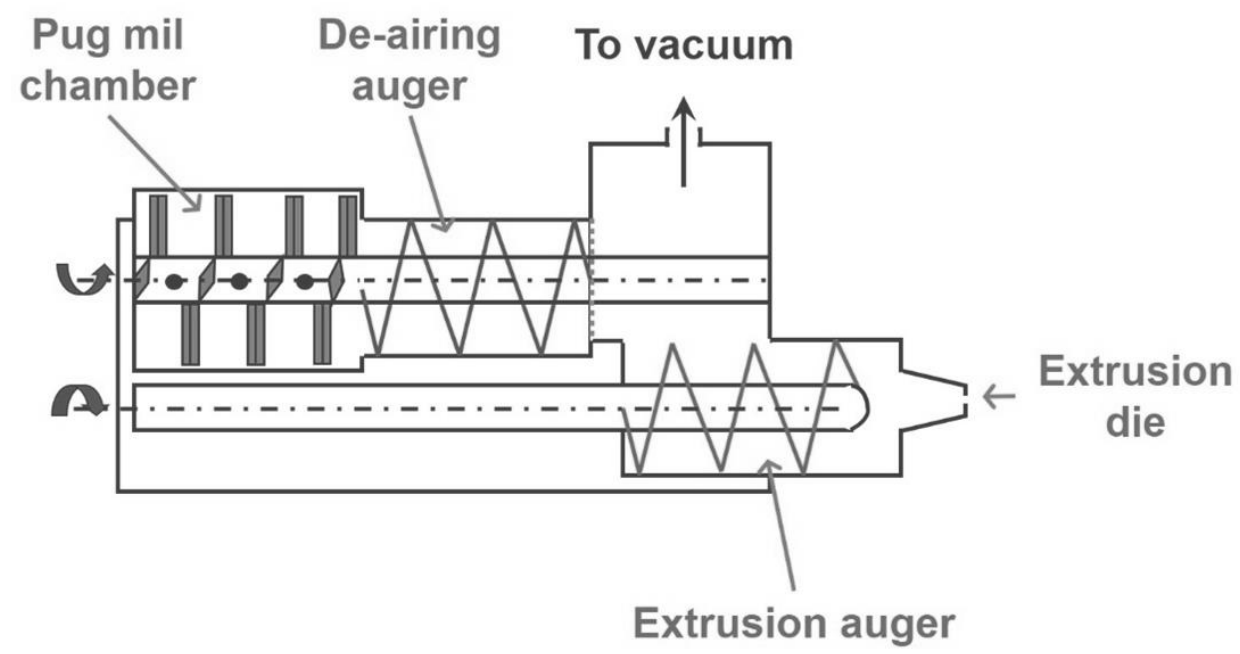

Figure 9: Diagram of an auger extruder with vacuum system. 
a)

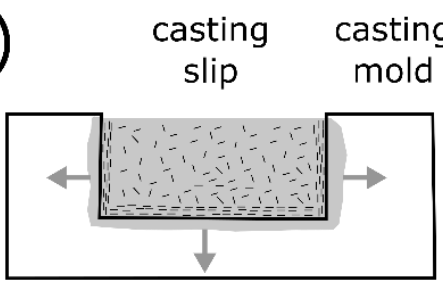

solvent suction b) casting slip

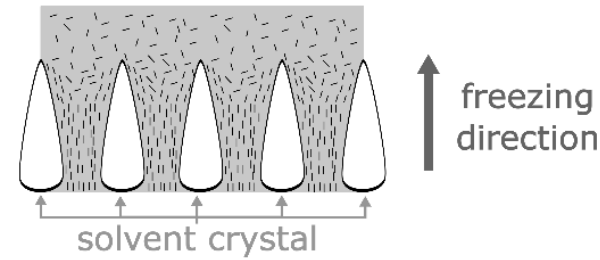

c)

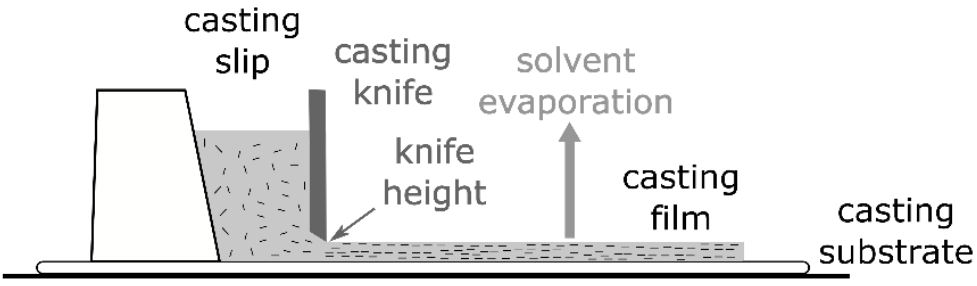

Figure 10: Schematic description of the other forming methods: a) slip casting; b) freeze-casting; c) tape casting.

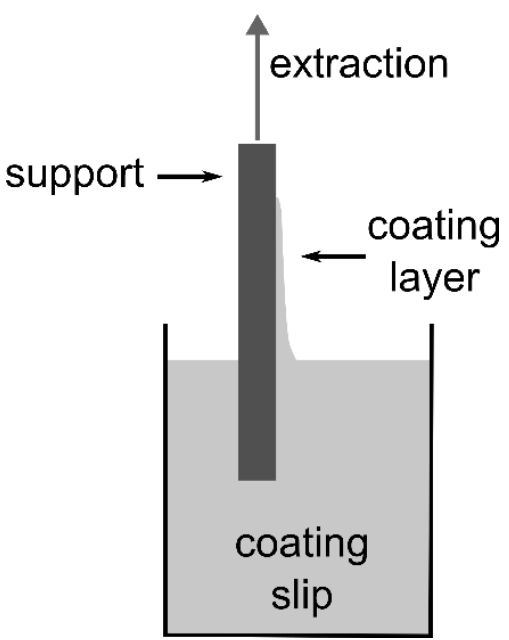

Figure 11: Process for membrane (flat) support dipping. 

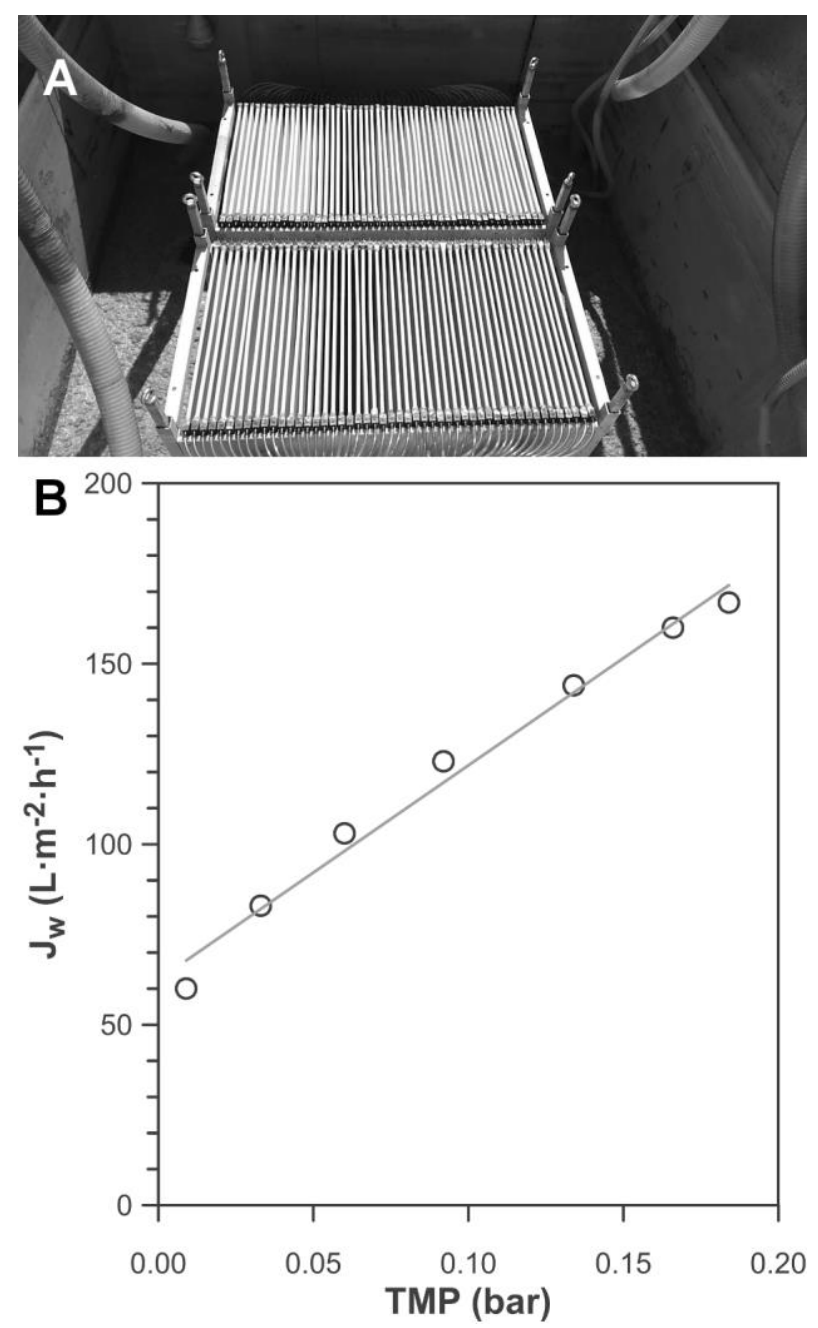

Figure 12: Use of low-cost ceramic membranes for membrane biological reactor (MBR): A) view of the ceramic membrane modules inside the tank and $B$ ) plot of water flow $\left(J_{w}\right)$ versus transmembrane pressure (TMP) in water conditioning tests of the membranes in the reactor. 


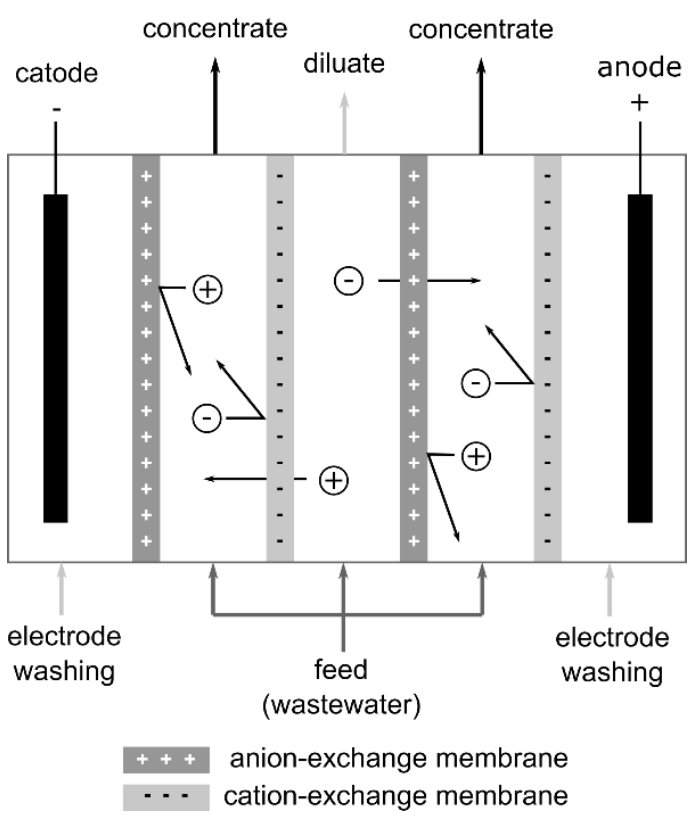

Figure 13: Scheme of an electrodialysis unit.

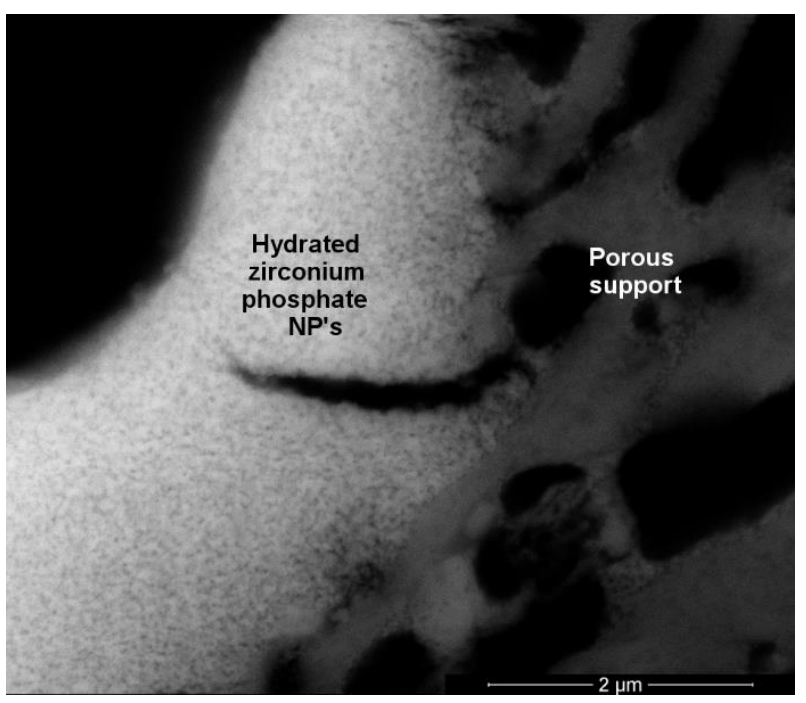

Figure 14: SEM image of a layer of nanoparticles of hydrated zirconium phosphate deposited over the surface of a pore inside the porous support. 